\title{
LA ARQUEOLOGÍA DE LA ARQUITECTURA. APLICACIÓN DE NUEVOS MODELOS DE ANÁLISIS A ESTRUCTURAS DE LA ALTA ANDALUCÍA EN ÉPOCA IBÉRICA
}

\author{
THE ARCHAEOLOGY OF ARCHITECTURE. \\ NEW MODELS OF ANALYSIS \\ APPLIED TO STRUCTURES \\ OF ALTA ANDALUSIA \\ IN THE IBERIAN PERIOD
}

JULIA SÁNCHEZ $(*)$

La realidad del edificio no consiste en las paredes y el techo, sino en el espacio interior en que se vive.

Lao-Tsé (siglo VI a.n.e.)

\section{RESUMEN}

Desde finales del siglo XIX surgieron nuevas teorías sobre el espacio arquitectónico, basadas sobre todo en la filosofía de Lao-Tsé. El espacio interior fue considerado la esencia de la arquitectura, estando representado por el cuerpo humano y experimentado como síntesis de todos los sentidos. Posteriormente, el espacio adquirió una dimensión cuatridimensional al incorporar el movimiento a las tres euclidianas. Desarrollando estos conceptos, las nuevas aportaciones enfocadas hacia el estudio pormenorizado de la arquitectura han conducido a la creación de una nueva disciplina denominada Arqueología de la Arquitectura. Desde este área se proponen nuevos modelos de análisis, de accesos y de visibilidad, que se aplican al espacio interior de las estructuras domésticas y funerarias ibéricas de la Alta Andalucía, completándose con el estudio de los principios ordenadores de la forma arquitectónica. Su objetivo final es reconocer las relaciones interespaciales que construyó la sociedad ibérica y las similitudes o diferencias que se producen en ambos tipos de unidades edificadas,

(*) Centro de Estudios Históricos. CSIC. Correo electrónico: jsanchez@ceh.csic.es.

El artículo fue remitido en su versión final el 7-IX-98. cuyos datos podrán ser contrastados en el futuro con los materiales asociados.

\begin{abstract}
New theories of architectural space, based on the philosophy of Lao-Tsé emerged at the end of nineteenth century. Interior space was now considered the core of architecture. Developing concepts of the movement of the human body in this space, new contributions focused on the detailed study of architecture have led to the creation of a new discipline called the Archaeology of Architecture. New models of analysis, based on access and visibility, are applied to the interior space of Iberian domestic and funerary structures in Alta Andalusia. The ultimate objective is to identify the interspatial relations on which Iberian society was based, and the similarities and differences which these relations produced in both types of built units.
\end{abstract}

Palabras clave: Arqueología de la Arquitectura. Espacio arquitectónico. Análisis de accesos. Análisis de visibilidad. Sociedad Ibérica. AltaAndalucía. Tumbas de cámara. Puente Tablas. Toya. Galera. Castellones de Ceal.

T. P., 55, n. $^{\circ} 2,1998$ 
Key words: Archaeology of Architecture. Architectural space. Access Analysis. Visibility Analysis. Iberian Society. Alta Andalucía. ChamberTombs. Puente Tablas. Toya. Galera. Castellones de Ceal.

\section{INTRODUCCIÓN}

Hasta hace pocos años, el estudio de la arquitectura quedaba en un segundo plano con respecto a otros restos arqueológicos, limitándose casi exclusivamente a la descripción formal y a la constatación de su técnica constructiva relacionándola con los materiales contenidos en ella.

Sin embargo, durante los últimos años, el creciente interés por los restos arquitectónicos ha permitido elaborar nuevos modelos de análisis que, derivados de las teorías que sobre el espacio se desarrollaron en el campo de la arquitectura desde mediados del siglo XIX, han alcanzado la disciplina arqueológica. Ésto ha dado lugar a un nuevo área de estudio denominadaArqueología de laArquitectura, centrado prioritariamente en la estructura doméstica.

Desde este nuevo enfoque, se conceptúa la casa como la unidad más elemental de la estructura socioeconómica, donde tienen lugar las funciones primarias de la sociedad, y como centro económico y social del asentamiento (Steadman, 1996). Al considerarse factores relacionados con aspectos culturales, político-económicos, sociales, subsistenciales o simbólicos, se supera el nivel descriptivo funcional que tradicionalmente se aplicaba a los restos arquitectónicos. Además, a menudo, se recurre a la etnoarqueología para tratar de descubrir la naturaleza de las relaciones sociales dentro de las unidades domésticas. La Arqueología de la Arquitectura se centra en el elemento contenedor, objeto físico formado por las paredes y el techo, cuya finalidad es determinar las relaciones espaciales (Hillier y. Hanson, 1984) donde se desarrollan las actividades humanas. Este aspecto puede valorarse por medio de la aplicación de los nuevos modelos de análisis propuestos dentro del campo de la "semiótica del espacio" (Steadman, 1996: 66).

En laArqueología española existen algunos trabajos que acusan la importancia de los restos arquitectónicos en el estudio de las sociedades del pasado. Entre ellos, en el ámbito de la Arqueología Medieval, se ha désarrollado una metodología de estratigrafía vertical por la que se estudian los ele- mentos murarios (Quirós, 1994; Caballero, 1995; Parenti, 1996) y, por lo que respecta al Mundo Ibérico, existen importantes estudios sobre su arquitectura desarrollados en el área valenciana (Bonet, 1995) y en Cataluña (Gracia et alii, 1994,1996). Sin embargo, todavía quedan por desarrollar los enfoques propuestos por laArqueología de laArquitectura que ha abierto un camino que es preciso extender a todas las áreas restantes de la Península Ibérica para extraer respuestas que ayuden-a una mejor comprensión de la sociedad.

El análisis del espacio interior en que se vive es la idea principal sobre la que se basa el estudio de las estructuras domésticas y funerarias ibéricas de laAltaAndalucía. Desde este enfoque, se pretende hacer un estudio comparativo entre ambas analizando primeramente la forma arquitectónica -como definidora de espacios- $y$, en segundo lugar, aplicando los nuevos modelos de análisis de accesos y de visibilidad con el fin de valorar las relaciones espaciales que se producen en ellas. Se excluyen los artefactos muebles para impedir la posible influencia que pudieran tener sobre la información que ofrezca el estudio del espacio arquitectónico de estas estructuras aunque, en un futuro, será necesario contrastar con los datos de los materiales incluidos en ellas. Aquí, el propósito es aportar un nuevo enfoque para el estudio de la arquitectura, como otro artefacto más del registro arqueológico, desde el punto de vista del espacio definido por la forma arquitectónica.

\section{LA ARQUEOLOGÍA DE LA ARQUITECTURA Y SUS ANTECEDENTES}

\section{EI espacio en arquitectura}

Desde la antigüedad, el espacio era una idea in abstracto reservada a las ciencias naturales y a filósofos comoAristóteles, Kant, Leibniz, Hegel, etc. (Ven, 1981) hasta que en la ségunda mitad del siglo XIX fue considerada esencial para el desarrollo de la teoría arquitectónica, siendo el pensamiento de Lao-Tsé (siglo VI a.n.e.) la base sobre la que se apoyaron sus teóricos. La idea de que el espacio interior (Ven, 1981: 23) reflejaba la superioridad del contenido sobre el continente fue tomada para afirmar que el espacio era la esencia de' la arquitectura.

El espacio, en cuanto idea arquitectónica, apareció por primera vez a principios de 1890 , coinci-

T. P., 55, n. ${ }^{\circ} 2,1998$ 
diendo con el primer movimiento de arquitectura moderna, el Art Nouveau, que rompió con el eclecticismo decimonónico. Es en este momento cuando la arquitectura se identifica con el espacio, convirtiéndola en Ars Magná con respecto al resto de las artes visuales (Ven, 1981: 312). A partir de entonces, historiadores del arte como. Hildebrand y Schmarsow, y arquitectos como Le Corbusier, Lissitzky, Gropius, etc., defendieron la nueva idea del espacio como concepto fundamental dentro de la arquitectura, siendo considerado como la encarnación de la actividad humana en el interior arquitectónico, "representando la' extensión del cuerpo humano, en tres dimensiones, en su existencia funcional" (Ven, 1981: 12).

Entre las diversas teorías que sirven de base a las propuestas por los nuevos modelos de análisis sobre el espacio arquitectónico, las de Schmarsow (1893) constituyeron una de las principales sobre las que trabajaron otros posteriormente, como por ejemplo la escuela holandesa De Stijl (1). Para este autor, la arquitectura se genera a partir del cuerpo humano, de modo que su principal objetivo sería el movimiento del mismo y sus extensiones en el espacio, quedando limitada por cuatro paredes, sin incluir necesariamente la cubierta ya que el espacio no siempre está techado. Piensa en tres modalidades de espacio: el tactil, el móvil y el visual, incorporando de este modo los sentidos del hombre en simultáneas y sucesivas experiencias en el espacio y en el tiempo.

Por su parte, la principal aportación de Hildebrand (1907) es que el espacio se percibe de dos maneras: a través de la 'visión pura' (imágenes en reposo) y a través de la 'visión cinética o visión en movimiento' (imágenes recibidas a través de los ojos del espectador en movimiento) introduciendo de esta forma el elemento 'tiempo'. Posteriormente, László Moholy-Nagy (1947; 1967), diseñador de la escuela alemana Bauhaus (2), define la idea del espacio como ley física, afirmando que éste es la relación entre la posición de los cuerpos y apoyando

(1) El movimiento De Stijl y la revista del mismo nombre fueron fundados en 1917 por los pintores Piet Mondrian y C.E.M. Kupper (conocido como Theo van Doesburg). De Stijl era partidaria de la abstracción, unificación de las artes y de la "creciente determinación del espacio" (Mondrian, 1945: 44).

(2) La Bauhaus, bajo el nombre de "Bauhaus Estatal de Weimar", se inauguró en 1919 bajo la dirección del arquitecto Walter Gropius. La meta inicial de la nueva escuela fue que artesanos y artistas debían levantar juntos la construcción del futuro y consr truir se convirtió en la actividad social, intelectual y simbólica. En abril de 1933, la Gestapo precintó la Bauhaus que, en ese momento, dirigía el arquitecto Mies van del Rohe (Droste, 1991). la idea de la 'visión en movimiento'. Según su tesis, el espacio puede ser experimentado como síntesis de todos los sentidos: vista, tacto, oído, movimiento corporal y gusto.

Los cubistas van más allá de las tres dimensio-ı nes de la geometría euclidiana añadiendo el concepto de cuarta dimensión (Ven, 1981:239). Para ellos, el espacio arquitectónico adquiere un conceptó cuatridimensional producido por el movimiento del cuerpo humano debido a que éste proporciona diferentes imágenes en su desplazamiento, mientras que las dimensiones euclidianas implican dimensiones estáticas.

El arquitecto Le Corbusier (Jeanneret, 1960; 1970; 1971) luchó contra este concepto de cuarta. dimensión, afirmando que los sentidos del hombre sólo podían distinguir tres dimensiones en el espacio por lo que propuso una tendencia, el 'purismo', que evitaba las implicaciones simbólicas de esa cuarta dimensión. Sin embargo, posteriormente rehabilitó este concepto denominándole 'espacio inefable' o estado emocional por el que experimentar espacios definidos por series armónicas: Consideraba que la planta de las casas, como generadora de formas, controlaba la disposición del volumen y el orden de la circulación, subrayando la importancia de ésta afirmando que "arquitectura es circulación" (Jeanneret, 1960: 48).

Habitualmente, la arquitectura se diseña y construye como respuesta a una serie de condiciones previas derivadas de los hábitos o necesidades funcionales, o responder a propósitos sociales, políticos o ideológicos entre otros. En su tratamiento, sedestacan dos requisitos: la necesidad de privacidad y la necesidad de vivir en sociedad. Para que ésto se cumpla (GLC,1978), es preciso crear espacios públicos y privados por medio de la densidad, la distancia y la geometría, lo cual es posible a través del elemento 'forma', entendida como definidora de espacios.

El desarrollo de todos estos conceptos sobre el espacio, la circulación y la privacidad condujeron a la creación de nuevos modelos de análisis, en su mayoría centrados en los accesos, iniciadò por Faulkner (1963) y desarrollados por Hillier y Hanson (1984) (3), así como los elaborados por Hall (1968) que estudia la necesidad de espacio perso-

(3) Se destaca que los análisis de accesos aplicados en Arqueología de la Arquitectura han sido iniciados por un arquitecto, Faulkner, y por Hillier y Hanson que desarrollan su labor en la Barlett School of Architecture and Planning, University College London. 
nal del ser humano (Proxemic) (4) dentro y entre estructuras arquitectónicas. Por lo tanto, aspectos fundamentales en la nueva disciplina como el estudio del uso del espacio, el movimiento, la visibilidad y otros, pueden completar los análisis tradicionales de los restos arqueológicos ampliando notablemente su conocimiento.

\section{Los nuevos modelos de análisis de la Arqueología de la Arquitectura}

Teniendo en cuenta todo lo anterior, esta disciplina va a desarrollar diferentes metodologías según las necesidades que se desprenden de los restos arqueológicos, algunos de cuyos modelos de análisis se citan a continuación.

\section{La estratigrafía vertical}

Consiste en un análisis exhaustivo de los parámentos con el fin de ordenar los procesos de construcción, restauración y destrucción en secuencias completas que abarcan los diversos momentos constructivos (Caballero, 1995). Se desarrolla sobre todo en el campo de la Arqueología Medieval debido a la continuidad histórica de su arquitectura. En Italia (5), donde se utiliza este método desde hace aproximadamente 20 años, los arqueólogos han contado desde un principio con la ayuda de los arquitectos, cada vez más interesados en las diferentes obras de fábrica y sus técnicas constructivas, así como en arqueometría.

\section{El análisis funcional y simbólico: la perspectiva anglosajona}

Los arqueólogos ingleses y americanos han desarrollado otros planteamientos para el estudio del registro, sobre todo doméstico, referidos generalmente a sociedades prehistóricas del Próximo Oriente, Europa y Mesoamérica, para las que se tiene en cuenta, además, información etnoarqueológica. Esta línea de trabajo deriva del estudio realiza-

(4) El término Proxemic no tiene traducción directa al castellano. Se refiere al estudio de la percepción y uso del espacio personal (Hall, 1968: 83). Aquí se utilizará para analizar una de sus variables: la visibilidad relativa.

(5) La importancia de los trabajos de autores como Brogiolo, Parenti, Mannoni y Quirós, entre otros, ha propiciado la aparición de una revista especializada llamada Archeologia dell'Architettura (1996), que nace como suplemento de la revista Notiziario di Archeologia Medievale, donde hasta ese momento existía un epígrafe con el mismo nombre. do por Clarke sobre las casas de la Edad del Hierro en Glastonbury (Clarke, 1972), donde se reconocen los factores sociales -división del trabajo, jerarquía social, expresión simbólica- a través de los restos arquitectónicos en un enfoque característico de la Nueva Arqueología. En este contexto, en el que se define la vivienda como 'Unidad Básica de Producción' (UBP), su estudio podría ser indicativo de la estructura general de la comunidad (Steadman, 1996).

Por otro lado, el apoyo de estudios etnográficos permite comprender aspectos que no son evidentes en el registro arqueológico. Por ello, Wilk y Rathje (1982) proponen cuatro categorías de funciones: producción y distribución reconocibles arqueológicamente, y transmisión y reproducción que sólo se podrían conocer a través de los modelos etnográficos, ya que no son fácilmente observables en arqueología.

Otros autores estudian la "comunicación canónica" (Blanton, 1994) para tratar de averiguar los principios simbólicos o cosmológicos representados en la estructura. Sus análisis van más allá de la definición estándar de la casa como la más pequeña unidad de producción económica, introduciendo aspectos como distribución de riqueza, estilo, organización, género y edad, así como las relaciones entre costo de materiales y construcción, accesibilidad, privacidad y conexiones entre las diferentes áreas.

Desarrollando el camino abierto por Blanton, Hodder $(1990,1994)$ considera no sólo la organización socioeconómica dentro de la vivienda, sino también los aspectos simbólicos comprendidos en la estructura. Desde estos supuestos, la preparación de comida, la colocación de figuritas femeninas y la situación de las sepulturas de niños y mujeres en los alrededores de la casa, asocian a ésta con la idea de nutrición. Para Tringham (Tringham et alii, 1992), interesada en el valor simbólico de los objetos al igual que Hodder, los niveles de incendio de una casa de Opovo representan la muerte simbólica de la casa causada por la muerte del cabeza de familia. De este modo, construye sus modelos basados en los aspectos materiales, entre los que incluye los restos arquitectónicos.

\section{El medio ambiente y la conducta humana}

Por otro lado, Rapoport y Kent estudian el uso simbólico del espacio, la conducta humana en todos sus aspectos, la comunicación no verbal y el 
crecimiento de la complejidad social en la estructura doméstica. Rapoport (1990), desde hace varios años, se interesa por la naturaleza de las relaciones entre la conducta humana y la construcción de su medio ambiente, asegurando que la forma de la arquitectura viene determinada por un sistema de actividades, entendidas como expresiones de estilo de vida y de cultura. Considera que la organización espacial es un aspecto más fundamental que la forma o los materiales, ya que "expresa significados y tiene propiedades simbólicas" (Rapoport, 1978: 26). Kent (1990) propone un modelo para determinar por qué unas sociedades compartimentan más sus casas que otras. Estudia las estructuras domésticas de 73 sociedades, estableciendo cinco niveles de complejidad basados en la organización social y política, la especialización económica y la división del trabajo. A partir de su estudio, llega a la conclusión de que cuanto más sociopolíticamente compleja es una sociedad, el uso del espacio y la arquitectura están más segmentados, por lo cual aumentaría la necesidad de lugares privados.

\section{El análisis sintáctico del espacio}

Ésta es un área de investigación en crecimiento que estudia la relación del espacio dentro del edificio incluyendo aspectos de accesibilidad, interrelación espacial y el significado social que subyace tras la organización de ese espacio (Hillier y Hanson, 1984), tanto dentro como entre las estructuras arquitectónicas (Steadman, 1996). Los recientes trabajos en este campo han conducido a otro área de investigación del uso del espacio, íntimamente relacionada con la anterior, que deriva de los estudios de Hall (1968) basados en el deseo de espacio personal. Aspectos claves de estas áreas de investigación son los análisis de accesos y de visibilidad y serán los que se apliquen a las estructuras domésticas y funerarias de la Alta Andalucía.

\section{a) Análisis de accesos}

Comienzan a desarrollarse con el estudio de Faulkner (1964) sobre castillos y casas escocesas. Este autor confeccionó un modelo de distribución interna analizando la comunicación entre los espacios, creando gráficamente el primer modelo de 'análisis de accesos'. Posteriormente, Hillier y Hanson (1984) propusieron otro, basado en el de
Faulkner, denominado "análisis gamma" (Hillier y Hanson, 1984: 143) añadiendo valores a cada espacio según la 'permeabilidad' de cada uno de ellos con respecto al espacio de entrada, que ha sido seguido por muchos investigadores (Yiannouli y Mithen, 1986; Boast y Yiannouli, 1986; Foster, 1989).

El análisis de accesos se basa en las relaciones sintácticas del espacio, considerando su disposición como un modelo de permeabilidad en términos de conexión interespacial (Hillier y Hanson, 1984). Implica la presencia de límites espaciales y de puertas de acceso, cuya importancia no reside tanto en que pueden abrirse como en que pueden cerrarse (Foster, 1989), actuando de control de paso a un ambiente determinado. La permeabilidad atiende al ordenamiento espacial, al control de su acceso y al movimiento (¿la cuarta dimensión de los cubistas?) que se desarrolla entre los mismos, lo cual revelaría las relaciones sociales que se establecen entre los habitantes de la estructura y entre éstos y los individuos ajenos a la misma (Hillier y Hanson, 1984).

Sin embargo, dado que la aplicación de los análisis gamma no evidencia la presencia de las áreas de actividad, formadas por exclusión de los recorridos circulatorios, ni de los elementos auxiliares incluidos en las mismas, se recurre a la teoría arquitectónica donde el estudio de la circulación ocupa un lugar principal. Los recorridos son, por naturaleza, lineales y tienen un punto de partida que conduce, a través de una serie de secuencias espaciales, hasta el lugar de destino (Ching, 1995). Si tenemos en cuenta el axioma matemático de la geometría euclídea de que la distancia mínima entre dos puntos es la línea recta, y el ser humano la utiliza en sus recorridos, la conexión de dos puertas de acceso por medio de una vía de comunicación ('visión cinética') creará, por exclusión, áreas susceptibles de contener actividades ('visión pura') de diversa índole. Por otro lado, dentro de estas áreas, pueden existir levantamientos auxiliares -bancos, repisas, nichos, peldaños, etc.- que provoquen un cambio de dirección, o una parada en la circulación, debido a la tendencia natural del movimiento humano hacia lugares que significan cambios (GLC, 1978: 110) -lugares en oposición a nuestro entorno, ya sean rincones, esquinas, puertas, muros planos, arcos, zonas amplias o estrechas, elevaciones, etc.por lo que esos elementos auxiliares adquirirán un significado que va más allá de su valor de uso y, por lo tanto, podrán modificar el valor del espacio que los contienen. 


\section{b) Análisis de visibilidad}

Otro área de investigación, directamente relacionada con los análisis de accesos, es la iniciada por Hall (1968) quien basa su trabajo en la percepción del espacio personal dentro y entre estructuras arquitectónicas, siendo necesaria la definición de sus límites para identificar los espacios públicos y los privados. Según su teoría, la percepción del espacio humano es una síntesis de los sentidos corporales: visión, audición, movimiento, olfato y gusto, que parece seguir la idea del espacio que expresó Moholy-Nagy (1947).

La visión, o reconocimiento visual de la percepción del espacio, constituye una información fundamental para el individuo (Gubern, 1992: 20), ya que, según Doddwell (en Gubern, 1992: 1) el noventa por ciento de la información de un hombre normal procede de los canales ópticos. Su cualidad transespacial, ya que actúa a distancia, crea una gradación visual según se dispongan los umbrales que, como líneas divisorias (Ven, 1977) entre lo público y lo privado, pueden variar los porcentajes de visibilidad. Por lo tanto, los umbrales serán los elementos de control utilizados por la unidad social que habita cada estructura para restringir ciertas áreas a individuos ajenos a la misma, que suelen localizarse "fuera del flujo de circulación" (Sanders, 1990: 68).

Analizar la forma arquitectônica, como elemento primario definidor de espacios, $y$ las relaciones espaciales a través los accesos y la visibilidad implica, por tanto, penetrar en una dimensión dinámica que permite trabajar con aspectos relacionados con la estructura y la ideología de la sociedad. Ésto convierte a estos estudios en una prometedora línea de investigación que aún está por desarrollar. La aplicación de Sändérs (1990) de análisis de visibilidad, sonido, olfató y èspacio tactil a dos casaś de Myrtos, Creta, ha servido de base pära la realización de este estudio.

\section{LA ARQUITECTURA IBÉRICA DE LA ALTA ANDALUCÍA}

Antes de iniciar el estudio de las casas y tumbas de cámara ibéricas es preciso hacer una breve introducción sobre la sociedad que las construyó. La Alta Andalucía es una de las áreas donde se han desarrollado más estudios del territorio encaminados a conocer las características y la evolución del poblamiento en época ibérica (Ruiz y Molinos, 1993).

Este tipo de trabajos han roto con la tendencia tradicional de excavación de necrópolis (Ruiz, 1987) iniciando un estudio sistemático en área de poblado. Durante el sigloVI a.n.e. se observa la presencia de pequeñosoppida en altura, en oposición a los asentamientos de la vega. En el sigloV, el triunfo de los oppida sobre las pequeñas unidades agrarias "opone dos sistemas aristocráticos diferentes, pero sobre todola consolidación de aquél que definirálas características del modelo de ocupación territorial del Alto Guadalquivir" (Ruiz, 1993: 107). Los patrones de asentamiento en esta fase parecen indicar que en este momento se produce la "máxima atomización" (Ruiz, 1983:114) entre aristócratas y sus clientelas. A inicios del siglo IV a.n.e., las relaciones.comerciales van a ser fluidas; como lo demuestra la gran cantidad de cerámica ática que penetra en la zona (Sánchez, 1992), lo que parece testimoniar que esta aristocracia ha conseguido gestionar con éxito un modelo económico excedentario.

La consolidación de la aristocracia se refleja arqueológicamente en la ordenación jerárquica de las viviendas y en la compleja configuración de las estructuras funerarias. Éstas han sido uno de los elementos más llamativos, por lo que la tradicional preferencia por sù excavación ha supuesto que, hasta los años 80, se desconociera el proceso real de la sociedad ibérica (Ruiz, 1987). Sin embargo; la presencia de enterramientos en cámaras de especial complejidad arquitectónica ha suscitado propuestas explícitas respecto a la posibilidad de que sean versiones funerarias de las residencias principales de ciertos sectores' de la sociedad ibérica (Almagro, 1982; Olmos, 1982). De este modo, se habrían adoptado las características propias de las estructuras domésticas para construir lás moradas de los difuntos.",

Esta propuesta abre un 'marco para la comproba' ción del funcionamiento interno de casas y sepulturas que permita reconocer lás pautas del diseño $y$ las concepciones que subyacen a estos dos tipos de construcciones. Los presupuestos básicos de los que parte este trabajo se centran, por tanto, en discernir si la lógica constructiva interna de casas y tumbas es similar y si pueden extraerse conclusiones de tipo social a partir de estos análisis. Se estudian las tumbas de cámara mejor conocidas de las necrópolis de Toya, Galera y Castellones de Ceal, situadas en la cuenca del Río Guadiana Menor. Respecto a la arquitectura doméstica de la zona, el

T. P., 55, n. ${ }^{\circ} 2,1998$ 
único poblado del que se disponen plantas completas es el de Plaza de Armas de Puente Tablas sobre el río Guadalbullón, cercano a las necrópolis citadas, considerado como característico de los asentamientos de tipo medio (Ruiz, 1993) (Fig. 1).

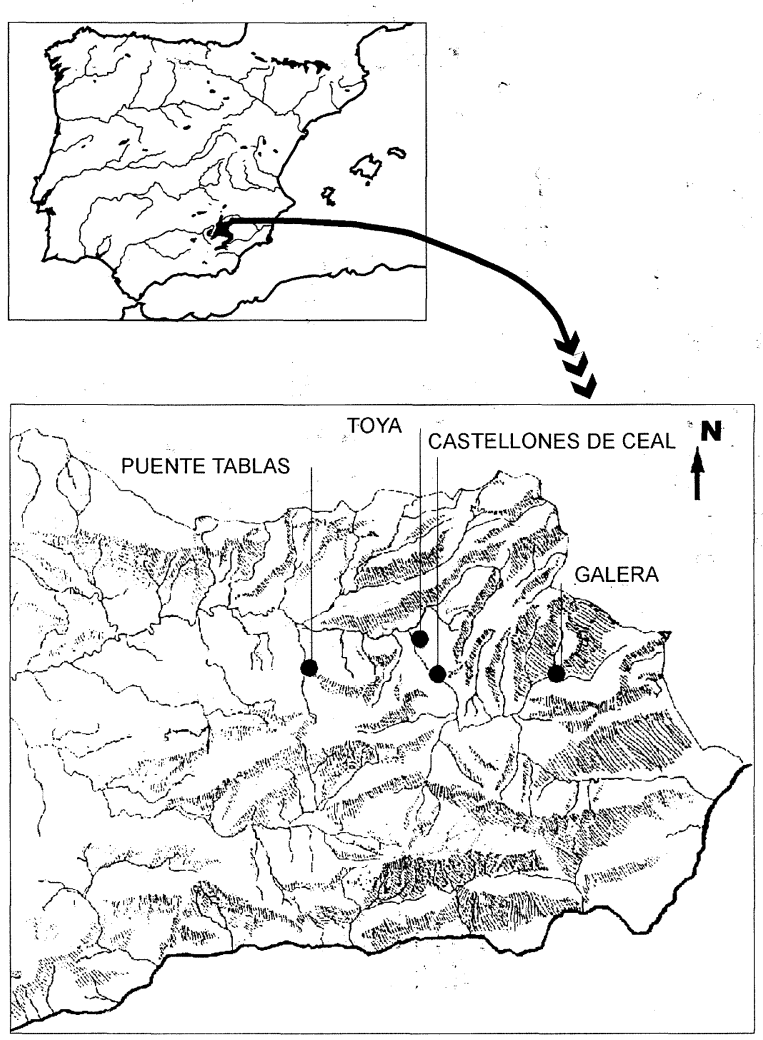

Fig. 1. Situación de las estructuras domésticas y funerariaś ibéricás en la Alta Andalucía.

\section{Las estructuras arquitectónicas}

Entre finales del sigloVIII y mediados del siglo VII a.n.e. (Ruiz y Molinos, 1993), el poblado de PuenteTablas (Fig. 2) aparece rodeado de fortificaciones "jalonadas de bastiones-contrafuertes rectangulares" y se generaliza la casa cuadrada, compartimentada. Hacia mediados del sigloVI se rediseña el urbanismo y se fija la estructura de algunas calles que se desarrollarán desde ese momento hasta el final de la vida del asentamiento. El poblado se compone de manzanas rectangulares cuyo muro medianero, que recorre toda su longitud, recoge las estructuras de las casas dispuestas perperdicularmente.

Las casas número 1, 2 y 5 (Fig. 3) (6) correspon-

(6) Todas las plantas de las estructuras estudiadas se han digitalizado a escala con el programa Autocad, partiendo de las pu-

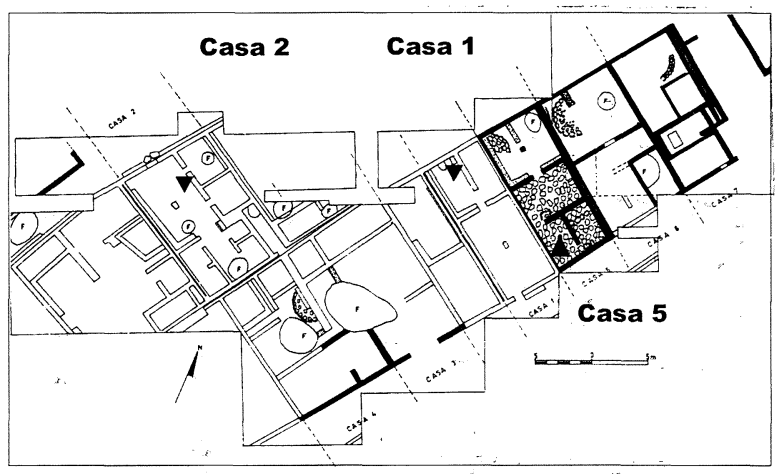

Fig. 2. Emplazamiento de las casas 1,2 y 5 del poblado de Plaza de Armas de Puente Tablas (basado en Ruíz y Molinos, 1990: 221).

den al siglo IV a.n.e. y forman parte de una manzana que ya existe desde el sigloVI. Se elevan directamente sobre el suelo, sin zanjas de cimentación, con un zócalo de piedra continuado con adobe, generalmente revocado. Respecto a la construcción de elementos secundarios, aparecen bancos y muretes en diversas estancias y tres peldaños en la casa 2, que indicarían un segundo piso dedicado a "almacén en altura" (Ruiz, 1995: 104). Esta casa es la más compartimentada, con siete espacios, frente a la número 1, con tres. Los pavimentos aparecen enlosados en algunas zonas y, en otras, con una fina capa de yeso.

En cuanto a las sepulturas, el área del Guadiana Menor se distingue por el uso de cámaras, con acceso horizontal, para enterramientos individuales y colectivos, cuyos paralelos han sido establecidos en el mundo griego y etrusco (García y Bellido, 1935; Blázquez, 1960) o púnico (Fernández de Avílés, 1942). Las estudiadas aquí de Gáléra (Cabré y Motos, 1920) son las tumbas 26 - de planta circular-, las númerớs $65,75,82$ y 106 - de planta en forma de "P" (García Bellido, 1945) y la 119 -también en forma de "P", compartimentada- que se sitúan cronológicamente entre los siglos VI y III-II (Fig. 4), disponiendo todas ellas de corredor de acceso. La cámara de Toya $(\mathrm{Ca}-$ bré, 1925; Mergelina, 1943-44) fechada én el siglo IV, se compartimenta en 5 estancias, mientras que la cámara 11/145 de Castellones de Ceal del siglo IV-III a.n.e. (Chapa y Pereira, 1988, 1991; Chapa et alii, 1984, 1990, 1991) consta de un úni-

blicadas por Ruiz y Molinos (1990) para Puente Tablas. De Galera, las publicadas por Cabré y Motos (1920). De Toya, la publicada por Mergelina, (1943-44) y la de Ceal por los datos del cuaderno de campo de Fernández Chicarro (1956). 


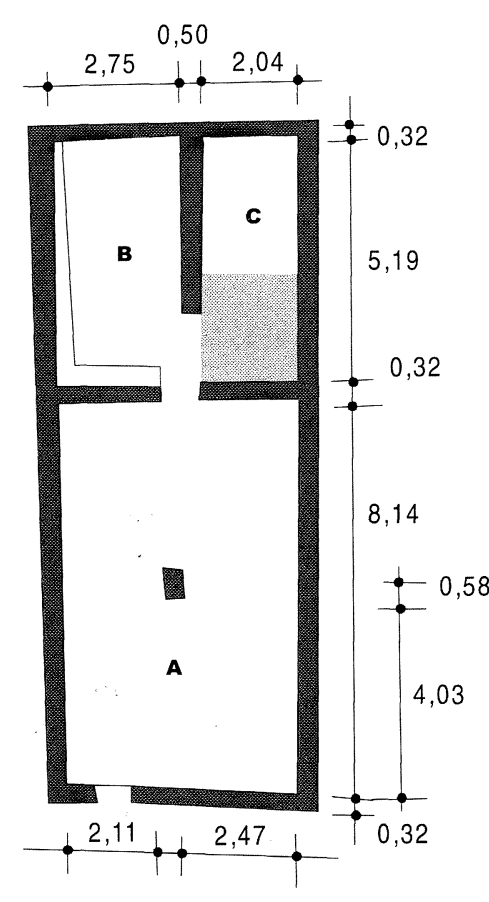

Superficie útil: $67,54 \mathrm{~m} 2$. Espacio A: $41,96 \mathrm{~m} 2$. Espacio B: $14,63 \mathrm{~m} 2$. Espacio C: $10,95 \mathrm{~m} 2$.
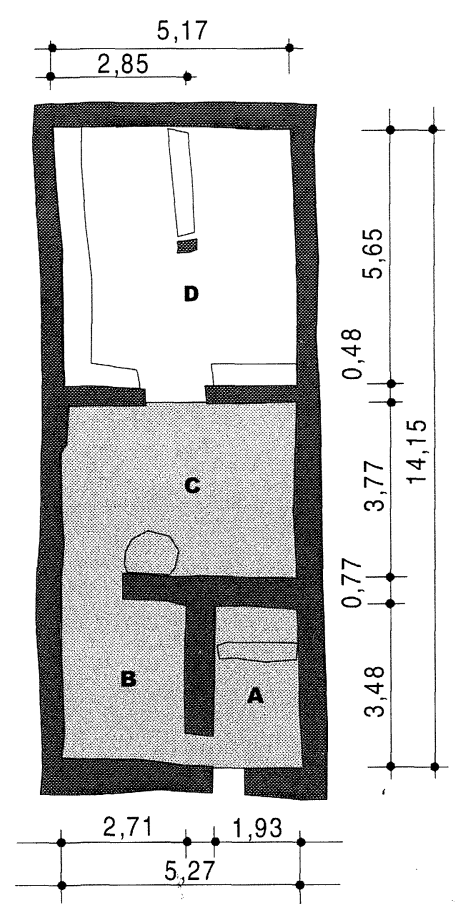

Superficie útil: $70,24 \mathrm{~m} 2$.

Sup. A: $6,69 \mathrm{~m} 2$

Sup. B: $9,72 \mathrm{~m} 2$

Sup. C: $19,51 \mathrm{~m} 2$.
Sup. D: $30,06 \mathrm{~m} 2$.

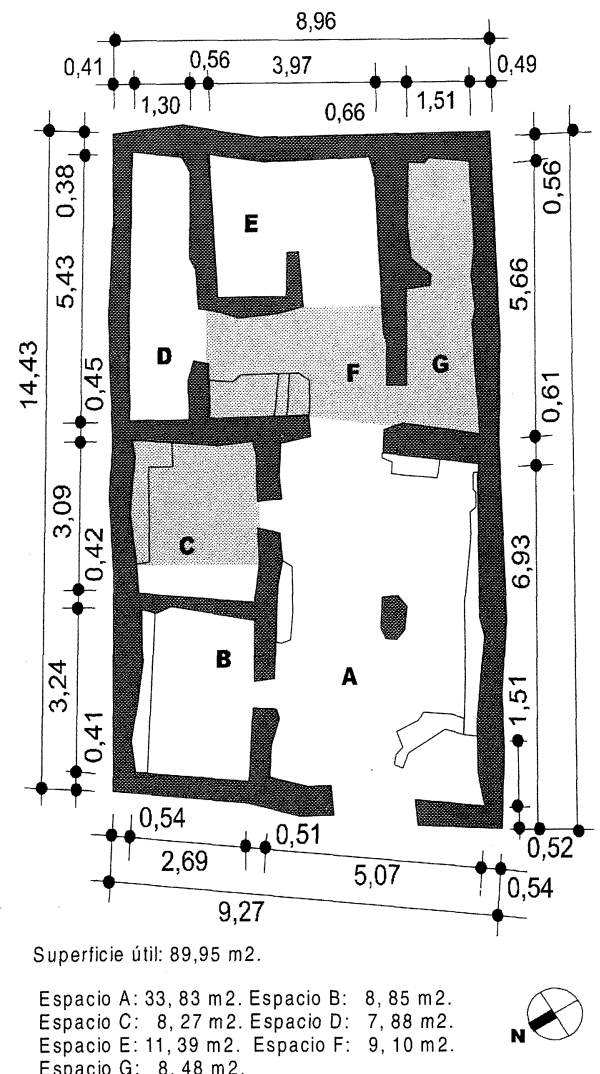

Espacio E: $11,39 \mathrm{~m} 2$. Espacio F: $9,10 \mathrm{~m}$.

Espacio G: $8,48 \mathrm{~m} 2$.

Fig. 3. Planta de cotas de las casas de Puente Tablas (digitalización basada en Ruíz y Molinos, 1990).

co espacio, desconociéndose el corredor en ambas (Fig. 5).

Las tumbas, a diferencia de las casas, se construyen exentas y se cubren con tierra formando un túmulo visible al exterior o, como en algunos casos de Galera, excavadas en la roca. Paredes y, a veces, pavimentos se enlosan para posteriormente recibir una capa de enlucido sobre la que se pintan motivos florales y/o geométricos y generalmente se cubren con losas adinteladas de piedra. Disponen de elementos auxiliares construidos de obra como bancos, hornacinas, fosas, peldaños, nichos y estantes.

Para el estudio de los espacios domésticos y funerarios, dado que quedan definidos por la disposición formal, se consideran elementos primarios los muros perimetrales -o continente-cuya función no es solamente técnico-estructural, sino que permite crear dos tipos de espacios, el exterior y el interior. Los elementos secundarios son aquellos que segregan el interior y su número estará relacionado con el nivel de complejidad establecido en cada estructura, estimándose que a mayor compartimentación social, el uso del espacio y la arquitectura estarán más segmentados (Kent, 1990). Se consideran también los elementos auxiliares ya que pueden variar la jerarquización espacial.

\section{Mediciones.}

Como consecuencia de las mediciones lineales, se ha podido observar que la ubicación central de los pilares en los patios de las casas y de la cámara 75 de Galera, así como el murete que subdivide la cámara 119 de Galera, son el resultado de soluciones estructurales de cubrición debido a la longitud de sus muros perimetrales. Las losas de piedra que cubren las tumbas habrían tenido una longitud máxima de $3,75 \mathrm{~m}$. y de 4,60 m. los rollizos de madera que cubrirían los patios -en los casos más desfavorables-, frente a los $1,85 \mathrm{~m}$ y $2,60 \mathrm{~m}$. que miden respectivamente debido al levantamiento de los pilares o muros medianeros. De estos datos se 


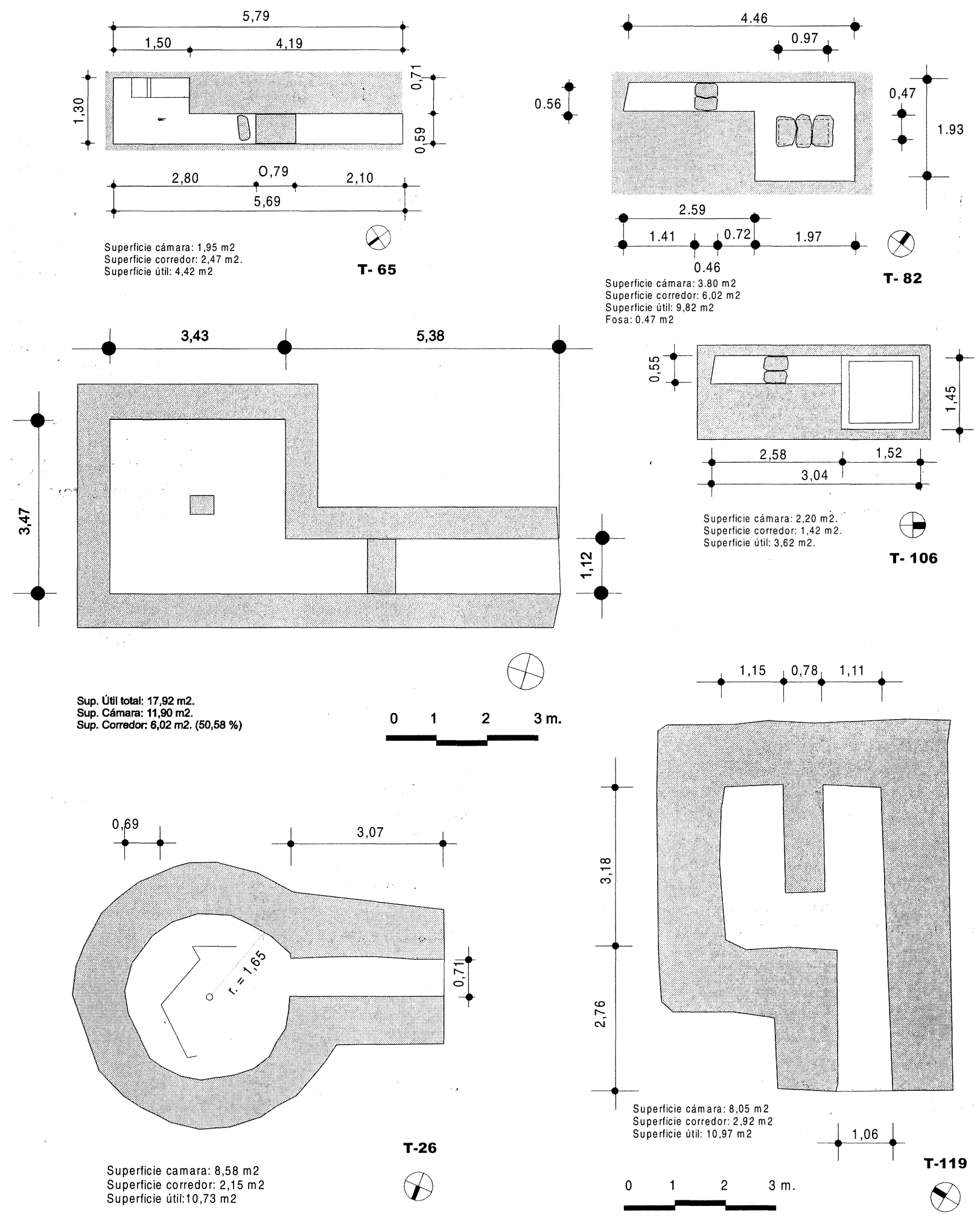

Fig. 4. Tumbas de cámara de la necrópolis de Galera. Planta de cotas (digitalización basada en Cabré y Motos, 1920). 


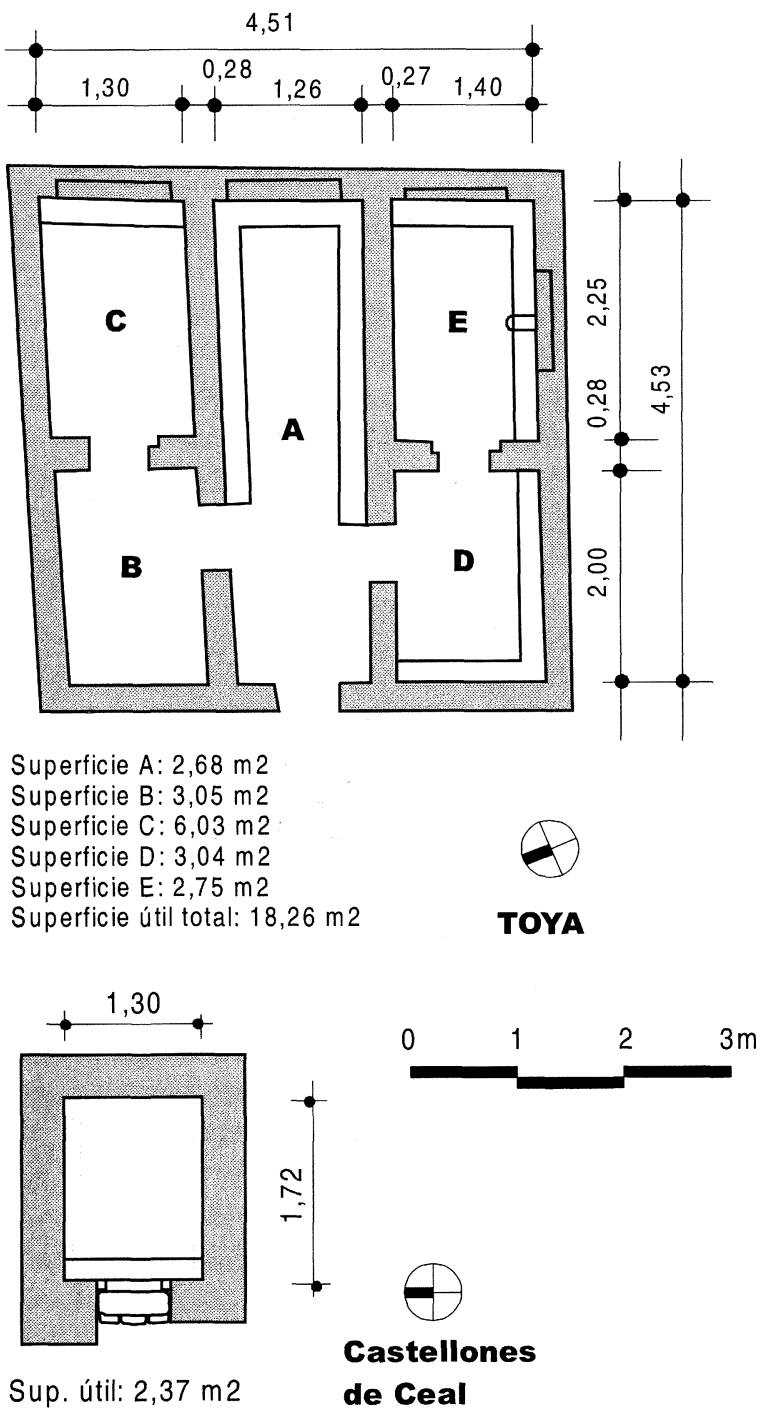

Fig. 5. Tumbas de cámara de Toya y Castellones de Ceal. Planta de cotas (digitalización basada en Mergelina, 194344 y en los datos del cuaderno de campo de Fernández Chicarro, 1956 respectivamente).

puede deducir que, tanto la extracción de la piedra, acarreo y elevación sobre los muros de losas de excesiva longitud implicaba un gran gasto tanto energético como de material y, de igual manera, el ahorro de madera así como su tala y carga, sería la práctica común.

El cálculo de la superficie útil de casas y tumbas es un aspecto más en la investigación de la arquitectura para saber si se han producido construcciones similares o si, por el contrario, existen jerarquizaciones entre unidades completas o, dentro de éstas, entre los diversos espacios definidos. En cuanto a las casas de Puente Tablas (Fig. 3), la superficie útil de las números 1 y 5 se mantiene similar, en torno a los $70 \mathrm{~m} 2$, mientras que en la 2 aumenta un $40 \%$, del mismo modo que la longitud de fachada. Dada la regularidad de las dos primeras casas, se insinúa la previa planificación modular de las edificaciones, dato que se refuerza por situarse adosadas a un muro continuo que recorre toda la manzana, de la que forman parte, que parece haber sido construido antes que ninguna casa. La ampliación de estos módulos primarios se produciría a espensas de otros colaterales, caso que parece producirse en la casa 2. También parece existir cierta planificación en la construcción espacial de los patios, ya que la superficie mantiene cierta regularidad (entre 30 y 37 $\mathrm{m} 2$.), lo que marcaría su singularidad frente al resto de las dependencias de la casa.

Entre las tumbas de cámara, se observan fuertes diferencias en el total de la superficie útil oscilando entre $2,37 \mathrm{~m} 2$ de la tumba de Castellones de Ceal y los $18,26 \mathrm{~m} 2$ de Toya. Las tumbas de Galera miden entre 3,62 y 10,97 m2, a excepción de la número 75 que se aproxima a la de Toya con 17,92 m2. Por lo tanto, en cuanto a superficie, estas últimas dos tumbas quedan jerarquizadas frente a las demás. Sin embargo, la planificación parece existir por la manifiesta voluntad de incrementar la superficie de las cámaras en detrimento de los corredores, como se puede ver en Galera donde ocupan entre el $58 \%$ y el $79 \%$ del total.

Los elementos auxiliares como nichos, fosas, repisas, peldaños y bancos en las cámaras de las tumbas son casi la práctica común y, de ellos, únicamente nichos y repisas aumentarán la superficie útil por situarse elevadas. Dada la escasa elevación de los muros de las estructuras domésticas en el registro arqueológico, es imposible advertir la existencia de estos últimos elementos aunque no se descarta la idea ya que, actualmente, algunas casas de la zona los disponen de forma similar a los conocidos de la cámara de Toya. Los bancos son la construcción común entre cámaras (Toya y $n^{\circ} 65$ de Galera) y patios (casas 2 y 5) y su uso varía entre el $20 \%$ de media en las tumbas mientras que en las casas es del $8 \%$.

\section{ANÁLISIS DE LA FORMA}

La forma arquitectónica es el elemento primario que define el espacio. Las edificaciones que nos ocupan son paralelepípedos, compartimentados en 
su interior, que determinan un volumen espacial -a través del cual nos movemos- definido por elementos formales. Su arquitectura empieza a existir cuando el espacio comienza a ser conformado y estructurado por los elementos de la forma: horizontales (definición del nivel del suelo) y verticales (los muros que encierran un espacio y definen el volumen) (Ching, 1995).

Para analizar la forma espacial, es preciso tener en cuenta que lo habitual es que los espacios definidos por la arquitectura se encuentren interrelacionados "en función de su proximidad o de la circulación que les une" (Ching, 1995: 194).Y lo hacen en base a unos principios ordenadores que, considerados como artificios que permiten la coexistencia de varias formas y espacios de un edificio, se organizan atendiendo a las necesidades que tiene la unidad social de formas concretas, de agrupaciones en virtud de funciones análogas, de luminosidad, ventilación, de segregación para lograr intimidad, etc.

Entre las más elementales vías de relación espacial, la contigüedad es la más frecuente, por lo que se identifican con claridad todos los espacios ya que, en todos los casos, el plano que les une o separa es un límite físico y visual, que realza su identidad. Otro aspecto de relación es la vinculación espacial por medio de un tercero, necesario para conocer la conexión de las diferentes actividades que se puedan producir.

Existen, además, principios adicionales de organización que implantan un cierto orden en una composición arquitectónica (Ching, 1995: 332). Los principios de simetría (distribución equilibrada de formas y espacios iguales en torno a un eje o punto común) y de jerarquía (significación de una forma o espacio en virtud de su dimensión, forma o situación relativa) aparecen frecuentemente, tanto en casas como en tumbas, y su estudio ha permitido la creación de agrupaciones espaciales que señalan la ejecución de actividades similares y la definición de espacios singulares.

Las casas 1,5 y 2 se compartimentan en 3,4 y 7 espacios respectivamente. Mientras que en la casa 5 cada espacio funciona independientemente, unicamente relacionados por contigüedad y continuidad, en la casa 1 el patio se apoya en dos estancias, situadas simetricamente al fondo de la unidad, con las que se relaciona (Fig. 6). En cuanto a la casa 2, su complejidad espacial ha permitido la creación de dos conjuntos espaciales, formados por simetría, que ocupan toda la superficie útil. Su principal ca-

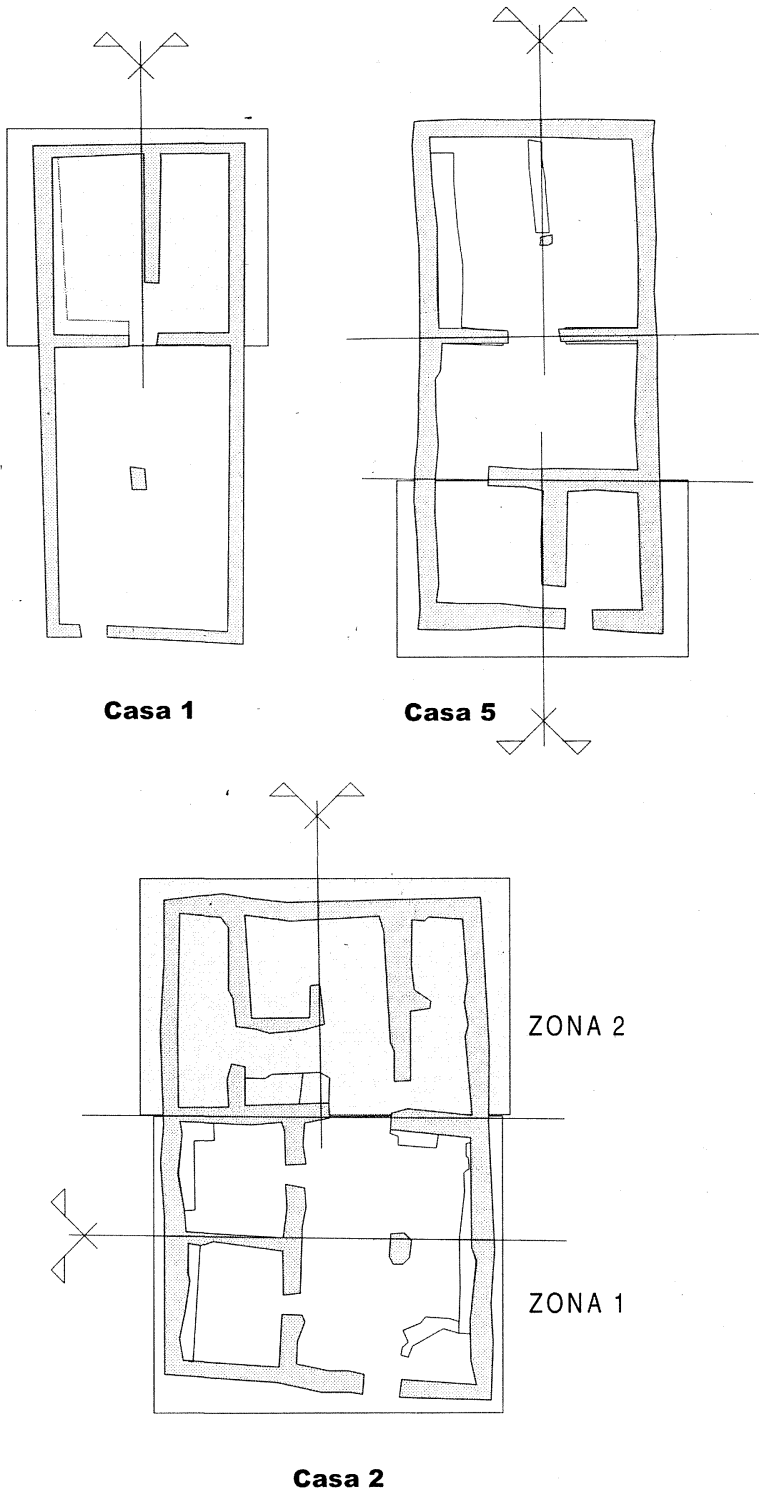

Fig. 6. Casas 1, 2 y 5 de Puente Tablas. Formación de conjuntos espaciales.

racterística está en que los ejes de ambos se cortan a 90 grados, en sentido transversal y longitudinal respectivamente, lo que indicaría la probable ruptura de continuidad de la actividad, en franca oposición. Un tercer tipo de actividad vendría señalado por el cambio de dirección, de horizontal a vertical, insinuado por los peldaños. En el segundo conjunto, cada espacio se relaciona por contigüedad quedando vinculados entre sí por medio de un tercero, $(\mathrm{F})$ que actúa de intermediario.

De igual manera, en Toya, el pequeño "vestíbulo" (Mergelina, 1943-44: 14) de recinto central (A) 
enlaza las estancias que derivan del mismo. Esta tumba es la única que se compartimenta en 5 espacios. Las otras cuentan con uno sólo-Castellones de Ceal-, con dos las de forma de "P" de Galera, y con tres las tumbas 26 y 119. A estos espacios secundarios habría que añadir otros situados en planos diferentes al horizontal, como nichos y fosas, que añadirían, además de superficie útil como se dijo arriba, cierta complejidad a la cámara.

El principio de simetría aparece en Toya y en la número 26 de Galera. En la primera, el eje se sitúa sobre la estancia central, haciendo bascular sobre el mismo las dos agrupaciones formadas por las cámaras laterales. Dada la cualidad de la simetría de distribución equilibrada, se establecería la similar importancia de los espacios situados a ambos lados del eje. Sin embargo, como se puede observar, el espacio E contiene dos nichos, una repisa y bancos corridos adosados a dos muros frente a su simétrico C, que sólo tiene un nicho, carece de repisa y la superficie de bancos es menor. Por lo tanto, el principio de simetría se desequilibra debido a la inclusión de elementos auxiliares que jerarquizarían unos espacios sobre otros. En la tumba 26, la simetría no se rompe en ningún momento ya que la forma circular de la cámara emplaza radialmente el eje sobre el corredor, y el tabiquillo que segrega aquélla se dispone perpendicularmente a este eje.

Pero, además, la regularidad de la forma es otro de los principios que jerarquiza un espacio sobre otro. Éste es el caso de los patios, en las casas, y de las cámaras, en las tumbas, frente al resto de las estancias, por lo que se convierten en espacios singulares dentro de ambos tipos de estructuras. Este aspecto, unido a que en los mismos se levantan similares elementos auxiliares de obra, podría relacionarse con la propuesta (Almagro, 1982, Olmos, 1982) de que las tumbas complejas reproduzcan residencias de ciertos sectores de la sociedad ibérica, con los filtros propios de su dedicación.

Otros elementos de diferenciación interespacial son los cambios de nivel en el pavimento y la decoración. La decoración, geométrica o floral, que adorna algunas tumbas de Galera (7) y la tumba de cámara de Castellones de Ceal, las jerarquiza frente a otras que carecen de esta cualidad. En Toya, la

(7) Según las referencias dadas a Cabré y Motos (1920: 14) por "tesoreros", la tumba 76 habría estado pintada con "escenas de caza, guerra y otras cuyo significado no comprendían". En la tumba número 2 , el pavimento estaba pintado en "blanco, rojo, negro y amarillo; su zócalo con trazos paralelos y otros motivos ornamentales geométricos y vegetales en lo que se conservaba en sus paredes" (id.: 64). decoración del intradós de la puerta de entrada a los espacios situados al sur, que contienen el mayor número de nichos, repisas y bancos, refuerza la importancia de esta zona sobre su simétrica; asímismo, el levantamiento del umbral de acceso a las cámaras B y D sobre el suelo responde a una intención predeterminada para intensificar su predominio sobre el resto. Los peldaños marcan diferenciaciones espaciales, pero esta vez de tipo vertical, de ascenso o descenso desde el inicio, reforzando la segregación espacial. En la casa 2, los tres peldaños indican ascenso a una probable segunda planta, mientras que en la tumba de Castellones de Ceal los peldaños descienden dando un significado de ingreso al mundo subterráneo propio de los muertos.

Por último, la forma externa de casas y tumbas marcan una gran diferencia entre sí. Las casas se alinean agrupadas en manzanas, visibles desde el exterior. Por contra, las tumbas se construyen exentas, y sus elementos estructurales quedan ocultos a primera vista ya que, la cualidad tumular de las necrópolis ibéricas sólamente permitiría visualizar la aglomeración de tierra vertida sobre las mismas.

\section{ANÁLISIS DE ACCESOS}

\section{Los análisis gamma}

Este modelo, propuesto por Hillier y Hanson (1984) para el interior de las casas, establece las profundidades o 'permeabilidades' a que se someten los diferentes espacios. A cada uno de ellos, representado con un círculo, se le asigna un valor de profundidad desde el exterior, quedando unidos por una línea aquellos que estén interconectados. Los que tienen el mismo valor se situarán gráficamente en la misma horizontal, observándose las propiedades básicas de las relaciones sintácticas del espacio: simetría/asimetría y distribuida/no distribuida. Las primeras indican la independencia interespacial y el control de un espacio sobre otro respectivamente, mientras que las segundas se refieren a la disposición de un sólo acceso en las distribuidas o de varios en las no distribuidas.

La aplicación de los análisis gamma a las casas y tumbas de la Alta Andalucía desarrolla un gráfico (Fig. 7) en el que se observan relaciones espaciales asimétricas en su mayoría, con la excepción de las estructuras más complejas estructuralmente, la casa 2 de Puente Tablas y la tumba de cámara de Toya, que combinan ambas propiedades. Tomando 


\section{PUENTE TABLAS}
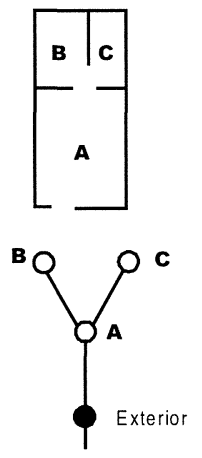

Casa 1

Casa 2

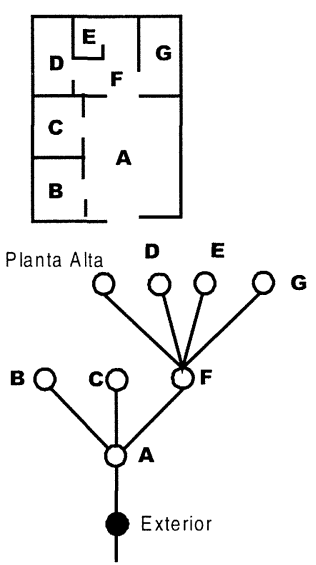

GALERA
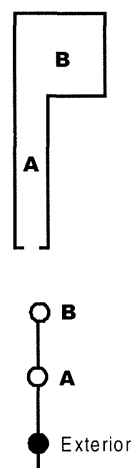

a)

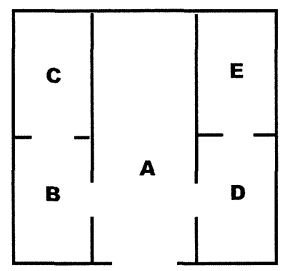

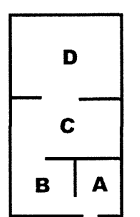

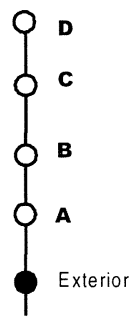

Casa 5
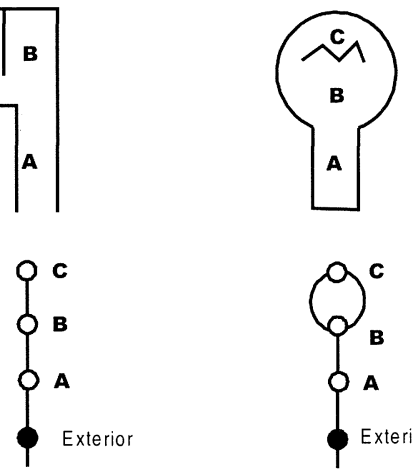

b) dientes entre sí con respecto a $\mathrm{B}$ y $\mathrm{D}$ pero simétricos con respecto a $\mathrm{A}$ al igual que $\mathrm{B}$ y $\mathrm{D}$. De este modo, los espacios situados a mayor profundidad quedarían doblemente controlados por sus antecesores y por el espacio de entrada. Dado que las estructuras disponen de un sólo acceso, tienen la propiedad de relación de distribuidas, excepto en la tumba número 26 de Galera donde el espacio segregado al fondo de la cámara permite su acceso por ambos lados.

El modelo, sin embargo, no tiene en cuenta otros aspectos que son visibles por medio de la red de circulación. Como puede observarse en el gráfico de análisis gamma de la casa 2, los espacios B, C y F se sitúan en la misma línea por lo que tendrían el mismo valor de profundidad. Sin embargo, no pueden ser conceptuados de la misma manera porque mientras que en $\mathrm{B}$ y $\mathrm{C}$ termina el recorrido, $\mathrm{F}$ es un espacio que se convierte en distribuidor de otros y por lo tanto controla aquellos que dependen de él. Por otro lado, obvia la inclusión de elementos auxiliares como pilares o bancos, nichos, hogares, etc., cuya situación interviene en el funcionamiento del recorrido circulatorio interno. Por lo tanto, la opción del estudio de la red de circulación, utilizada en la disciplina arquitectónica, es aquí oportuna para complementar los datos de los análisis gamma.

\section{El recorrido espacial}

En Arquitectura, el recorrido es considerado "como el hilo preceptivo que vincula los espacios de un edificio" (Ching, 1995: 246). Todos los recorridos son, "por naturaleza, lineales y tienen un punto de partida desde el cual se nos lleva a través de una serie de secuencias espaciales hasta que llegamos a nuestro destino" (Ching, 1995: 270). Sin embargo, la intersección de caminos crea otro tipo de configuraciones del recorrido como la radial, entre otras. Una vía principal de acceso recorre cada estructura, desde el exterior hasta el espacio más profundo, a la que se conectan otras, secundarias, para dar acceso a los diferentes espacios, produciendo nudos circulatorios que alcanzarán mayor grado de conflictividad allá donde la afluencia de caminos sea mayor. Teniendo en cuenta que es necesario un espacio mínimo de $68 \mathrm{~cm}$. de ancho (Neufert, 1972: 21) para personas en movimiento, el recorrido determina, por exclusión, la ubicación de otros susceptibles de utilización como áreas de actividad, o espacios en reposo. Dado que el recorrido se configura 


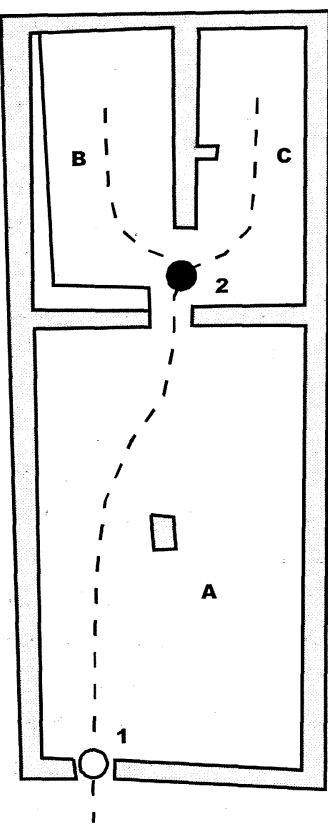

Casa 1

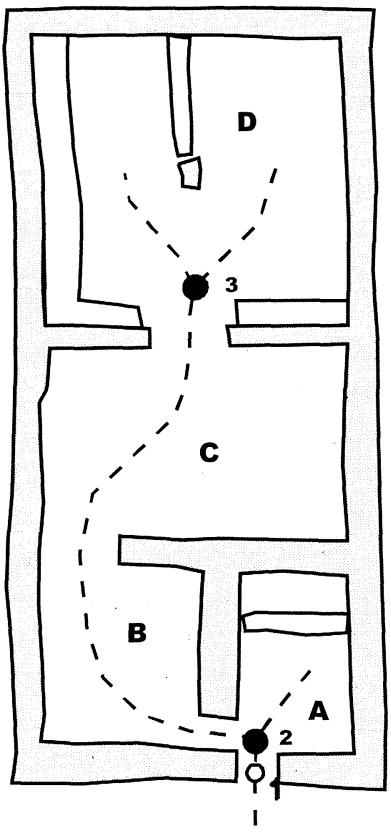

Casa 5
Fig. 8. Análisis de accesos. Recorrido circulatorio de las casas 1 y 5 de Puente Tablas.

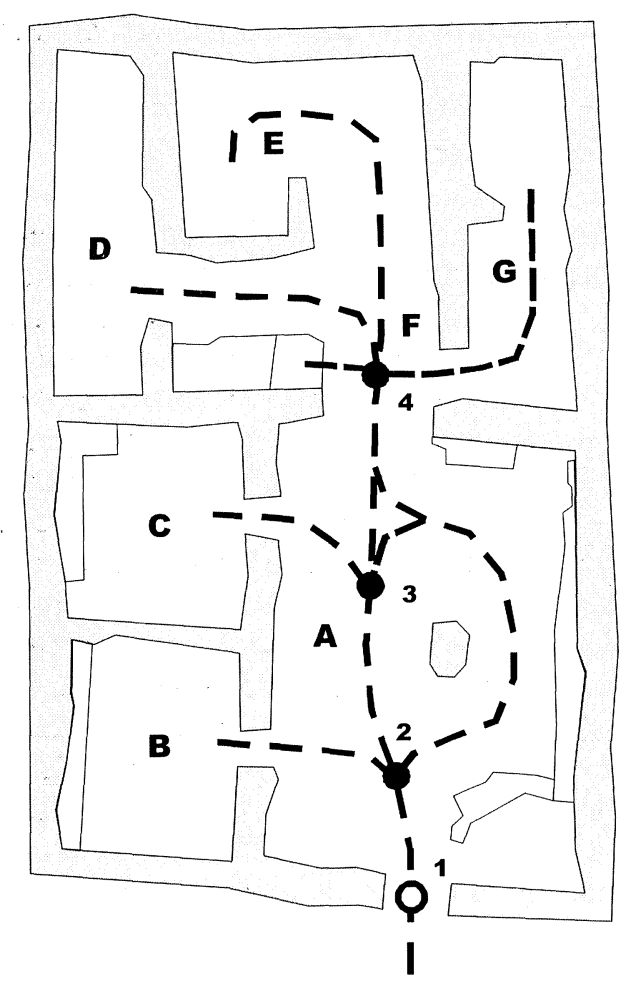

Fig. 9. Análisis de accesos. Recorrido circulatorio de la casa 2 de Puente Tablas. a través de las aberturas practicadas en los muros, la superficie de esas áreas quedará determinada por su situación, ya sea centrada o lateral.

En las casas 1 y 5 de Puente Tablas (Fig. 8), el máximo número de caminos que confluyen en un nudo es de dos, por lo que no se genera ningún conflicto en la circulación. Sin embargo, en el espacio F de la casa 2 (Fig. 9), se produce un nudo donde convergen varias vías configurando un recorrido de tipo radial, una de las cuales cambiaría el sentido horizontal a vertical dada la existencia de peldaños que subirían a una segunda planta. La amplia confluencia de caminos le convierte en distribuidor ya que no existe espacio físico para el desarrollo de ninguna actividad (Sanders, 1990). Los espacios que dependen de él serían funcionalmente preeminentes por ser donde se crea la máxima segregación (Foster, 1989) y donde acaba el recorrido (Ching, 1995). En el caso de Toya (Fig. 10), el único nudo que se forma está en la entrada (punto 2), distribuyendo radialmente la circulación en tres direcciones. La condición de distribuidor impediría la formación de otras funciones específicas, coincidiendo con la ausencia de bancos u otros elementos.

En las casas de Puente Tablas y en la tumba de Toya, la superficie y la disposición de las puertas fuerzan al recorrido a atravesar espacios abiertos a los que, sin embargo, no segrega convirtiéndose en una prolongación de los mismos (Ching, 1995). El caso de las tumbas de cámara de Galera es diferente porque el estrecho corredor ocupa todo el espacio circulatorio, estimulando la circulación hacia su lugar de destino: la cámara y, en concreto, hacia los

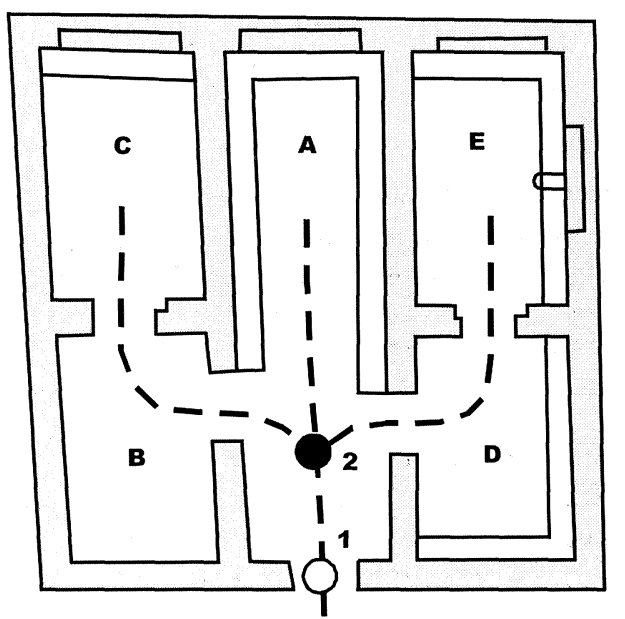

Fig. 10. Análisis de accesos. Recorrido circulatorio de la tumba de cámara de Toya. 
elementos auxiliares construidos en ella como nichos, repisas, fosas o bancos, donde se depositan las cenizas y los ajuares del difunto (Fig. 11).

Dentro de las cámaras funerarias existen diversos componentes arquitectónicos como fosas (Tumba 106 de Galera), levantamiento de umbrales so-
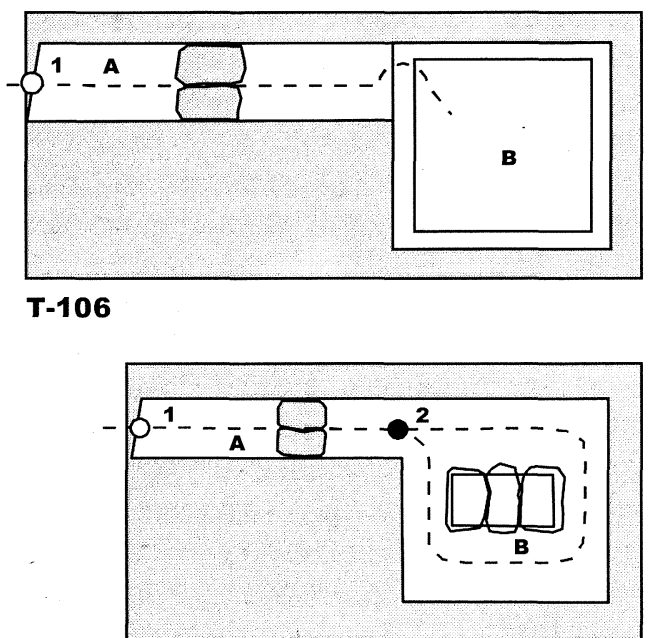

T-82

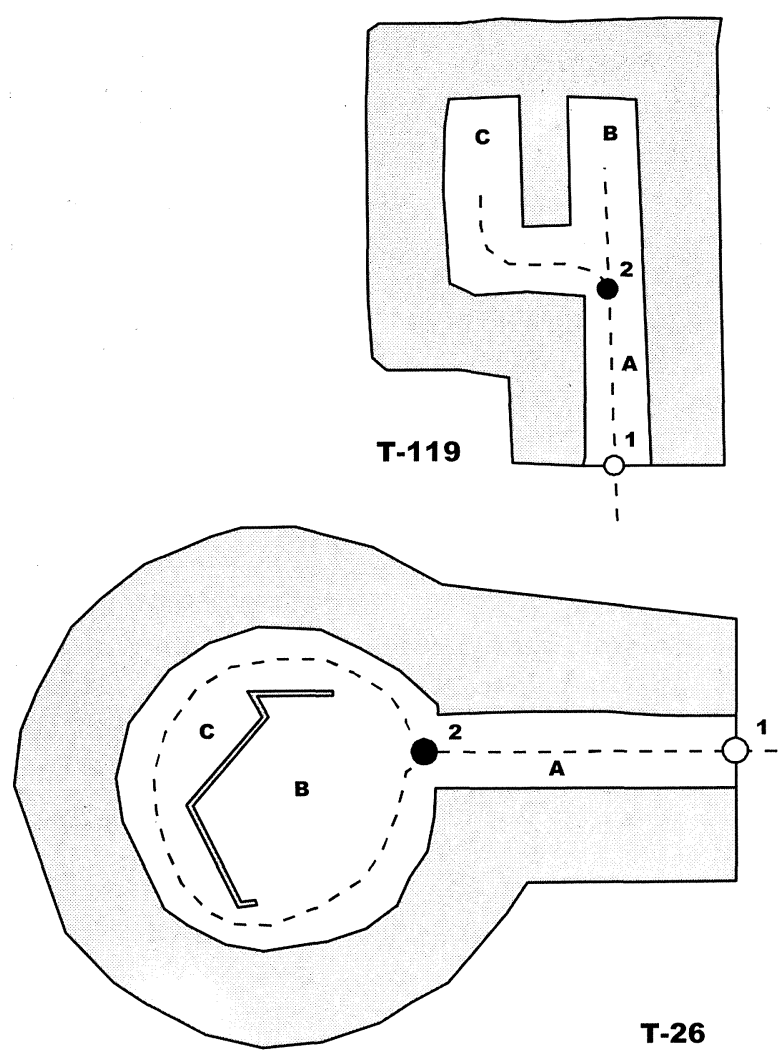

Fig. 11. Análisis de accesos. Recorrido circulatorio de las tumbas $106,82,119$ y 26 de Galera. bre el suelo (Toya), peldaños (Castellones de Ceal), losas (Tumba 82 de Galera), tabiquillos (Tumba 26 de Galera), pilares (Tumba 75 de Galera) o bancos, nichos u hornacinas (Tumbas de Galera y Toya) que modifican el trazado lineal de la circulación y obligan a dar un salto, más cualitativo que físico, a descender o a parar. Los obligados cambios en el recorrido indican que existe cierta complejidad en la estructura y fuerte voluntad en contrastar espacios para indicar el dominio jerárquico de unos sobre otros.

De la misma manera que, mediante la aplicación de análisis de accesos, se advierten los controles establecidos por la unidad social para reservar espacios específicos en una estructura arquitectónica, es posible reforzar la presencia de éstos a través de los porcentajes de visibilidad determinados por la situación de los muros y las aberturas practicadas en ellos.

\section{ANÁLISIS DE VISIBILIDAD}

Para que se produzcan los diferentes espacios públicos, semipúblicos o semiprivados y privados es preciso considerar cada estructura arquitectónica -ya sea un conjunto urbano o aislada- como un conjunto cerrado. En este trabajo, el análisis de visibilidad se aplica a estructuras previamente individualizadas, reconocidas como unidades domésticas o funerarias.

Para entender cómo se producen los diferentes espacios, desde públicos a privados, se propone el ejemplo de un espectador emplazado en un área abierta, en época ibérica, que tiene un poblado fortificado frente a él. El espacio que el individuo está ocupando es público, mientras que el poblado será privado porque todavía no le ha sido permitido el paso al mismo. Si las puertas de las murallas se abren, el espacio que antes era privado se ha convertido en público porque ha superado los controles de acceso, a excepción de las casas privatizadas por los muros de cerramiento. Sucesivamente, de forma similar, una vez se ha ingresado en cualquier casa, el carácter espacial se va modificando según se atraviesen los controles establecidos por la unidad social que los ha contruido y habita.

Los tabiques son el elemento constructivo que segrega espacialmente las construcciones primarias definiendo los diferentes grados de visibilidad. Las aberturas practicadas sobre los tabiques son los elementos que actúan de control y su disposición 
modificará los porcentajes de superficie pública, privada y semipública.

Para conocer la ubicación y ocupación de cada espacio, se trazan dos líneas imaginarias desde el centro de cada umbral con el punto de vista situado a la altura del ojo humano, cuya retina dispone de un ángulo visual de $240^{\circ}$ (Gubern, 1992: 22), y se dirigen hasta los límites establecidos por las barreras arquitectónicas. Los espacios situados detrás de las mismas serán de carácter restringido al visitante hasta que le sea permitido el paso al siguiente umbral. El primer punto de vista se situará en el acceso principal y los siguientes en cada puerta, $o$ vano, que cree diferenciación espacial y nunca se situarán en la de aquellos espacios que carezcan internamente de compartimentación, porque ya serían totalmente accesibles. Sucesivamente, de forma gradual, los espacios se privatizan hasta alcanzar su más alto grado en los situados más al fondo. Se podría argumentar que las tumbas, por su condición de enterramiento, son privadas en sí mismas. Sin embargo, una vez traspasado el primer umbral, la gradación entre espacios públicos y pri- vados se produce de igual manera que en las unidades domésticas.

El cálculo de la superficie ocupada por los distintos espacios se hace en porcentajes sobre la superficie útil debido a la variabilidad de las mismas. El resultado obtenido podría estar en relación con el número de personas que acceden a los mismos de manera que, a mayor privacidad, mayor restricción de paso y, al contrario, a mayor superficie pública, el control sería ejercido en condiciones más abiertas.

La diferente situación de los patios en las casas varía considerablemente el porcentaje de espacio privado. Mientras que en las números 1 y 2 se produce entre el $2 \%$ y el $5 \%$, en estancias pequeñas, en la número 5 lo hace con un $20 \%$ en el patio, de mayor superficie. (Fig. 12). La opuesta ubicación de los patios puede derivar del uso dado a ese espacio, indicando de este modo la diversidad funcional del mismo, de aspecto prioritariamente público en las casas 1 y 2 y más privado en la 5 . Por lo tanto, los elementos auxiliares situados en ellos: hogar, bancos, pilares o tabiquillos formarían parte de un

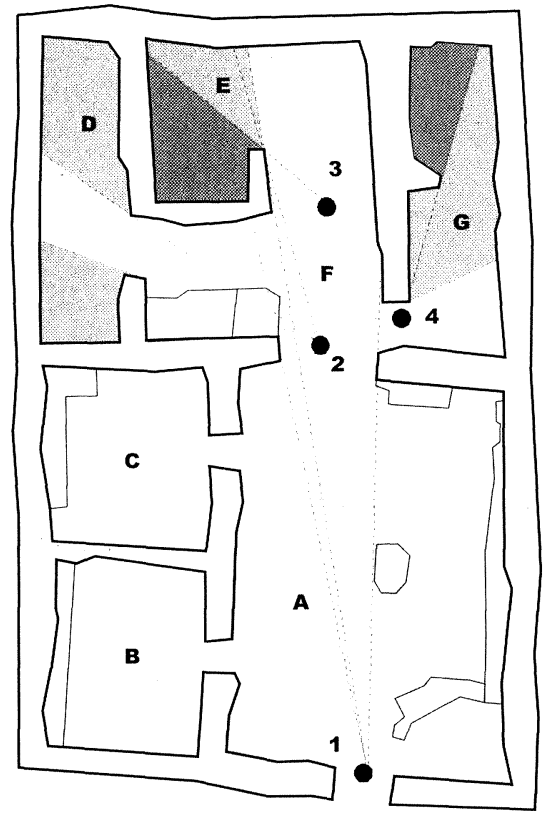

Casa 2

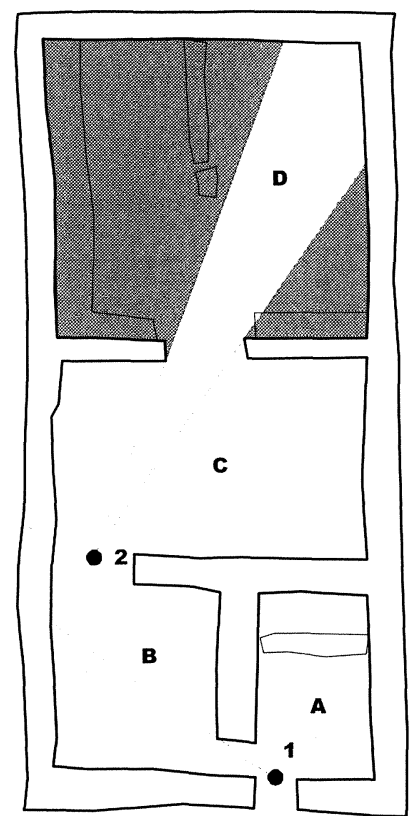

Casa 5

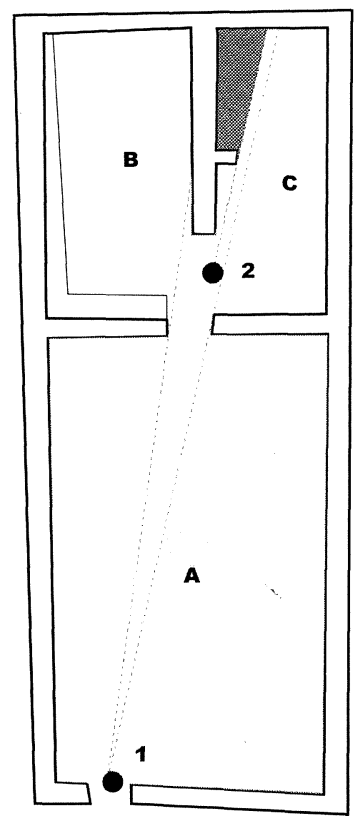

Casa 1

Fig. 12. Análisis de visibilidad de las casas de Puente Tablas. 
espacio público en las dos primeras y del privado en la última. Con respecto a los espacios semipúblicos, se da la característica que aumenta su superficie a medida que disminuye el público, siendo este aspecto indicativo de la mayor privacidad en la unidad arquitectónica.

En el caso de las tumbas de cámara con corredor (Fig. 13), dada la situación previa de éste, siempre se crea el espacio privado en las cámaras debido a que el segundo punto de vista se sitúa sobre las losas de cerramiento que dividen el corredor, ejerciendo de control e imprimiendo un fuerte sentido de privacidad.

Del análisis de visibilidad del primer grupo (tumbas números 65, 75, 82 y 116 de Galera) se verifica que todas las tumbas, excepto la número 65 , tienen mayor porcentaje de espacio privado que de público (éste varía entre el 30 y el $45 \%$ ). La menor

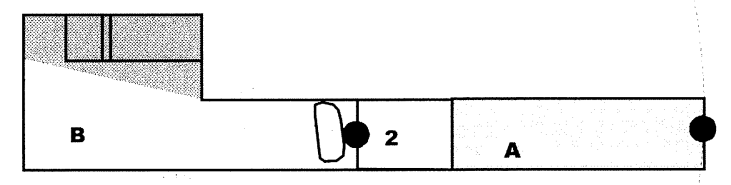

T-65
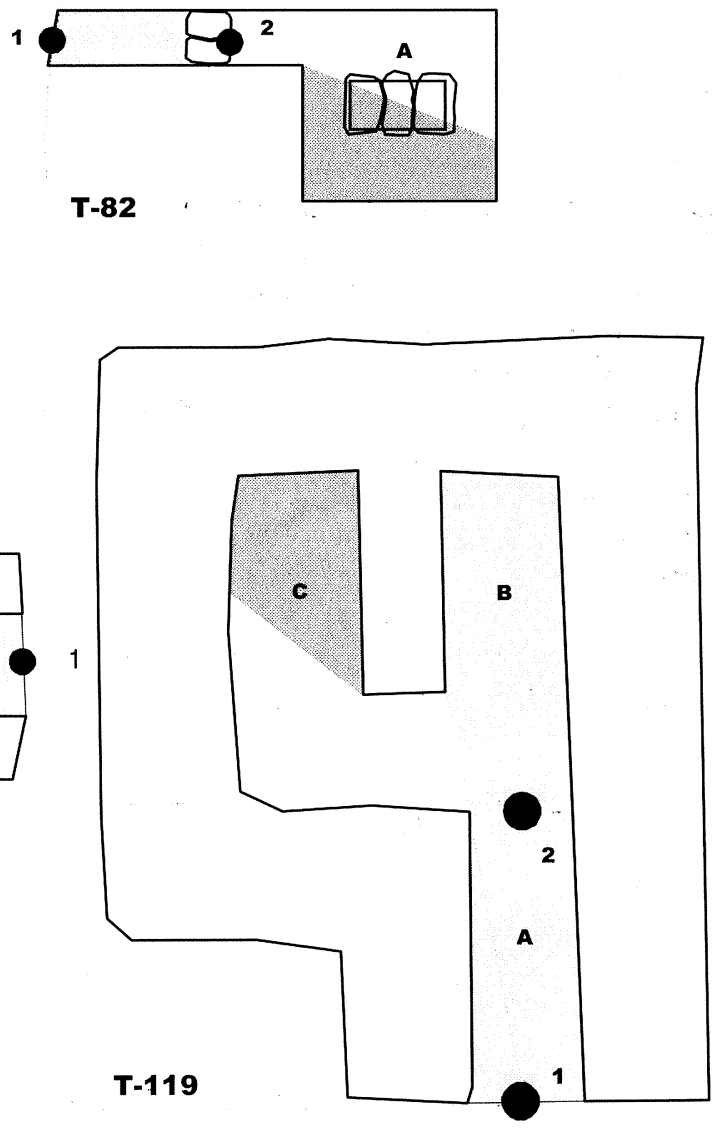

Espacio público

Espacio privado

Fig. 13. Análisis de visibilidad de las tumbas de Galera nº 65, 82, 75, 119 y 26. 
disposición de espacio privado en tumba 65 es resultado de la mayor superficie útil del corredor sobre la cámara, dado que ocupa un $27 \%$ más. En cuanto al segundo grupo, (tumbas 26 y 119 de Galera), los porcentajes relativos entre públicos y privados quedan fuertemente sesgados por el desconocimiento de la longitud total del corredor, pero existe predominio del espacio público en ambas, entre el $52 \%$ y el $59 \%$ sobre la superficie útil conocida. El comportamiento de los espacios semipúblicos es diferente en ambos grupos. En el primero ocupan casi el doble que los privados y son ostensiblemente mayores que los públicos, a excepción de la tumba 82 cuya gran superficie de espacio privado provoca la disminución de aquél. En las tumbas 26 y 119 , del segundo grupo, los espacios semipúblicos ocupan entre un $28 \%$ y un $40 \%$ respectivamente.

En la cámara de Castellones de Ceal, al carecer de corredor y de compartimentación interior, la visibilidad sería total una vez atravesado el umbral de acceso. El único aspecto privatizativo serían los peldaños de bajada que simbolizan el acceso al mundo de los difuntos. En Toya (Fig. 14), la medición de los porcentajes de visibilidad se hace sobre los que proporcionan las diversas estancias de la cámara. La disposición de sus espacios y la situación de las puertas de acceso regulan los porcentajes con escasas diferencias, de manera que reciben similar importancia los espacios de carácter público, semipúblico y privado. La jerarquización de los privados se acentuaría, como ya se ha in-

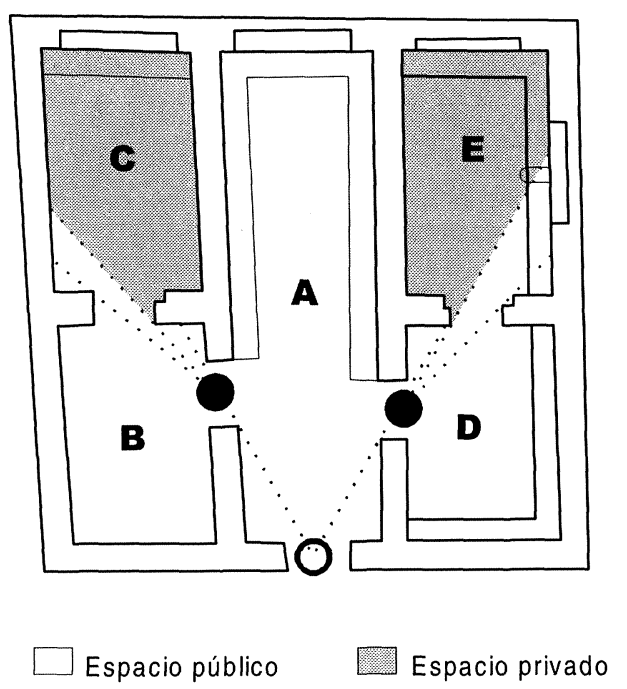

Fig. 14. Análisis de visibilidad de la tumba de Toya. dicado con anterioridad, por la inclusión de elementos que sirven de base a la ubicación de las cenizas de los difuntos y sus ajuares: bancos, repisas y nichos.

\section{CONCLUSIONES}

La estrategia práctica de este trabajo consistió en considerar los espacios definidos por la forma arquitectónica y la aplicación de los nuevos modelos de análisis propuestos desde la Arqueología de la Arquitectura, excluyendo los materiales asociados a la misma cuya contrastación será objeto de un estudio posterior.

Se ha comprobado que sin los datos de la ubicación de las puertas o vanos no es posible estudiar las relaciones espaciales que se producen dentro de las estructuras, ya sean domésticas o funerarias. Conociéndolos, se ha podido observar la formación de conjuntos espaciales que evidencian la creación de actividades de similar dedicación, su ordenación, vinculación y articulación predeterminadas, o los controles que establece la sociedad para acceder a determinados espacios que reserva para sí.

Como consecuencia del estudio de la forma arquitectónica y la medición lineal y superficial de cada estructura ha sido posible conocer la, más que probable, modulación previa de cada unidad doméstica de Puente Tablas.Asímismo, se advierte cierta planificación previa tanto en la construcción de espacios de similares características - los patios de las casas-, como en la agrupación formal del conjunto cámara-corredor de las tumbas de Galera o debido a la regularidad y simetría de la tumba de Toya.

La superficie y la compartimentación muestran jerarquizaciones espaciales entre unidades completas o de espacios simples sobre otros de menor consideración. Cuando se dan estos casos, los controles de acceso son mayores y se produce mayor complejidad en la gradación de visibilidad. Por otro lado, al realizar los análisis de visibilidad, se observa que la opuesta situación de espacios de superficie singular, en concreto los patios, muestra las preferencias de la sociedad por la diferente dedicación de los mismos. Sin embargo en las tumbas, dado que las cámaras (espacio singular) se sitúan siempre al fondo de la unidad funeraria, la privacidad siempre se dispone sobre ella y, precisamente sobre los elementos auxiliares que, normalmente, soportan las cenizas del difunto y los ajuares, sin variar su dedicación.

T. P., 55, n. $^{\circ} 2,1998$ 
A partir de los análisis expuestos, existen ciertos aspectos que apuntan a favorecen la sugerencia de que las tumbas de cámara del mundo ibérico reproducen las unidades domésticas de ciertos sectores de la sociedad. La visibilidad desde el horizonte las distingue porque las casas se alinean sobre el nivel de calle formando manzanas, mientras que las tumbas aparecen como un conjunto de múltiples elevaciones de tierra sin que se advierta la forma arquitectónica. Sin embargo, las similitudes aparecen estudiando el espacio arquitectónico. En ambos casos, el espacio primario está compartimentado y/o dispone de elementos distintivos arquitectónicos que permiten llevar a cabo los análisis propuestos. Por lo tanto, se puede estudiar su composición formal, realizar recorridos circulatorios y ver dónde y cómo se han establecido los controles de acceso y, dado que es factible hallar los porcentajes de espacios públicos y privados con respecto a la superficie útil construida, conocer las áreas que la unidad social se reserva para sí. En cada estructura existen espacios jerarquizados frente al resto y disponen de elementos auxiliares ubicados indistintamente en zonas públicas o privadas en las domésticas, y exclusivamente en las privadas en el caso de las funerarias. Por lo tanto, se puede argumentar que, en general, la sociedad construye sus espacios de forma similar aunque con los filtros propios de su dedicación.

Esta nueva línea de actuación propone estudiar la arquitectura bajo aspectos diferentes a los hasta ahora recogidos y, así, completar una investigación que contempla la colaboración interdisciplinar de investigadores como antropólogos y arquitectos, tal y como aconseja la Arqueología de la Arquitectura. Pero, sobre todo, es de destacar que no es tan importante el envolvente de una edificación como el espacio que ha formado, donde se vive, y esto hace que el futuro de la investigación sea francamente prometedor.

\section{AGRADECIMIENTOS}

Este trabajo forma parte del Proyecto de Investigación DGICYT PB95-0375: "El poblamiento ibérico en el sureste peninsular: una perspectiva espacial" dirigido por la Dra. Teresa Chapa Brunet (Departamento de Prehistoria, Facultad de Geografía e Historia. Universidad Complutense de Madrid), a quien quiero agradecer mi participación en el mismo y por quien fue posible su realización.
Asimismo quiero agradecer al arqueólogo D. Antonio Madrigal su desinteresada ayuda tanto profesional como personal, y a la Dra. M. ${ }^{a}$ Isabel Martínez Navarrete por sus consejos y revisión.

\section{BIBLIOGRAFÍA}

Almagro Gorbea, M. (1982): “Tumbas de cámara y cajas funerarias ibéricas. Su interpretación socio-cultural y la delimitación del área cultural ibérica de los bastetanos”. Homenaje a Conchita Fernández Chicarro. Ministerio de Cultura. Madrid: 249-257.

Archeologia dell'Architettura (1996): Supplemento ad Archeologia Medievale, XXII. Ed. All'Insegna del Giglio. Firence.

Blanton, R.R. (1994): Houses and Household, a Comparative Study. Plenum Press, New York.

Blázquez MARTínez, J.M. (1960): "La cámara sepulcral de Toya y sus paralelos etruscos". Oretania, 5: 233-244.

Boast, R. y Yiannouli, E. (1986): "Creating Space". Archaelogical Review from Cambridge, 5 (2): 136-140.

Bonet, H. (1995): El Tossal de Sant Miquel de Liria. La antigua Edeta y su territorio. Servicio de Investigación Prehistórica. Centre Cultural de Beneficència. Diputación de Valencia. Valencia.

Caballero Zoreda, L. (1995): "Método para el análisis estratigráfico de construcciones históricas o lectura de paramentos". Informes de la construcción, 46 (435): 37-46.

CABré Aguiló, J. (1925): “Arquitectura hispánica. El sepulcro de Toya". Archivo Español de Arte y Arqueología, 1: 73-101.

CABrÉ, J. y Motos, F. de (1920): La necrópolis ibérica de Tútugi (Galera, provincia de Granada). Junta Superior de Excavaciones y Antigüedades, 25. Madrid.

Clarke, D.L. (1972): "A provisional model of an Iron Age Society and its settlements system". In D.L. Clarke, (ed.): Models in Archaeology. Methuen, London: 801869.

Chapa, T.; Fernández, M.; Pereira, J. y Ruiz, A. (1984): "Análisis económico y territorial de los Castellones de Ceal (Jaén)". Arqueología Espacial, 4. Teruel: 223252.

Chapa, T.; Madrigal, A. y Pereira, J. (1990): “La cámara funeraria de los Castellones de Ceal ( Hinojares, Jaén)”. Verdolay, 2: 81-86.

- (1993): "Tipos de construcciones funerarias en el yacimiento de Castellones de Ceal (Hinojares, Jaén)". Homenaje a MiquelTarradell. CSIC. Barcelona: 411-419.

Chapa, T. y Pereira, J. (1988): "Excavación arqueología sistemática de los Castellones de Ceal. Campaña 1987". Anuario Arqueológico de Andalucía / 88, II. Sevilla: 304-307.

- (1991): “Los Castellones de Ceal (Hinojares, Jaén).

T. P., 55, n. ${ }^{\circ} 2,1998$ 
Informe de la Campaña de 1989". Anuario Arqueológico de Andalucía / 91, II. Sevilla: 165-170.

Chapa, T.; Pereira, J.; Madrigal, A. y López, T. (1991): "La sepultura 11/145 de la necrópolis ibérica de los Castellones de Ceal (Hinojares, Jaén)". Trabajos de Prehistoria, 48: 333-348.

Ching, F. (1995): Arquitectura: forma, espacio y orden. Ed. Gustavo Gili. México.

Droste, M. (1991): Bauhaus. 1919-1933. Editado por el Archivo y Museo de Diseño de la Bauhaus, Berlín. Alemania.

FAULKNER, P.A. (1964): "Castle planning in the fourteenth century". The Archaeological Journal, CXX: 215-235.

FERNÁNDEZ DE AvilÉs, A. (1942): "El aparejo irregular de algunos monumentos marroquíes y su relación con el de Toya”. Archivo Español de Arqueología, 15: 344347.

Fernández Chicarro, C. (1956): "Prospección arqueológica en los términos de Hinojares y La Guardia (Jaén)". Boletín del Instituto de Estudios Giennenses, III, 7: 101-119.

FOSTER, S. (1989): “Analysis of spatial patterns in buildings (access analysis) as an insight into social structure: examples from the ScottishAtlantic Iron Age". Antiquity, 63: 40-50.

García y Bellido, A. (1935): "La cámara sepulcral de Toya (Jaén) y sus paralelos mediterráneos". Actas y Memorias de la Sociedad Española de Antropología, Etnología y Prehistoria, 14: 67-106.

- (1945): La Arquitectura entre los Iberos. Madrid.

G.L.C. STUdy (1978): An Introduction to Housing Layout. The Architectural Press. London.

Gracia, F.; Munilla, G. i García, E. (1994): "Models d'análisi de l'arquitectura ibérica. Espai public i construccions religioses en medis urbans". Cota Zero, 10: 90-101.

Gracia, F.; Munilla, G.; García, E.; Playa, R.M. y Muriel, S. (1996): "Demografía y superficie de poblamiento en los asentamientos ibéricos del NE peninsular". En M." Ángeles Querol y Teresa Chapa (eds.): Homenaje al profesor Manuel Fernández-Miranda. Complutum Extra, 6 (II): 177-191.

GuBERn, R. (1992): La mirada opulenta. Exploración de la iconosfera contemporánea. Ed Gustavo Gili. México.

Hall, E. (1968): "Proxemics". Current Anthropology, 9: 243.

Hildebrand, A. (1907): "Problem of Form". En Painting and Sculpture. Stechert. Nueva York.

Hillier, B. y Hanson, J. (1984): The social logic of space. C.U.P. Cambridge.

Hodder, I. (1990): The domestication of Europe. Basil Blackwell, Oxford.

- (1994): "Architecture and meaning: the exemple of Neolithic houses and tombs". En M.P. Pearson and C. Richards (eds.): Architecture and Order. Routledge. New York: 73-86.
JeANNERET, Ch.E. (1960): Précisions sur un Etat présent de l'Architecture et de l'Urbanisme. Editions Vincent, Fréal \&Cie. Paris.

- (1970): Toward a new Architecture. Praeger. Nueva York.

- (1971): Le Modulor. A harmonious measure to the human scale universally applicable to architecture and mechanics. Mass., M.I.T. Press. Cambridge.

Kent, S. (ed.) (1990): Domestic Architecture and the use of Space. An interdisciplinary cross-cultural study. New Directions in Archaeology. C.U.P., Cambridge.

Mergelina, C. (1943-44): "Tugia, reseña de unos trabajos". Boletín del Seminario de Estudios de Arte y Arqueología, 10: 13-32.

Moholy-Nagy, L. (1947): Vision in Motion. Theobald. Chicago.

- (1967): The new vision. Wittenborn-Schulz. Nueva York.

Mondrian, P. (1945): "The Real Content of Art". En R. Motherwell (ed.): PlasticArt and Pure PlasticArt. Ed. Robert Motherwell. Nueva York.

NeufERT, E. (1972): Arte de proyectar en Arquitectura. Ed. Gustavo Gili. Barcelona.

Olmos, R. (1982). "Vaso griego y caja funeraria en la Bastetania ibérica." Homenaje a Conchita Fernández Chicarro. Ministerio de Cultura. Madrid: 259-268.

PARenti (1996): “Una visión general de la Arqueología de la Arquitectura". Actas de Arqueología de la Arquitectura. El método arqueológico aplicado al proceso de estudio y de intervención en edificios históricos. Junta de Castilla y León. Burgos: 13-22.

Quirós Castillo, J.A. (1994): "Contribución al estudio de la Arqueología de la Arquitectura". Arqueología y territorio medieval, 1. Actas del Coloquio Problemas en Arqueología Medieval. Universidad de Jaén, Jaén: 141 158.

RAPOPORT, A. (1978): Aspectos humanos de la forma urbana. Hacia una confrontación de las Ciencias Sociales con el diseño de la forma urbana. Ed. Gustavo Gili. Colección Arquitectura/Perspectivas. Barcelona.

- (1990): "Systems of activities ans systems of settings". En S. Kent (ed.): Domestic Architecture and the use of Space. An interdisciplinary cross-cultural study. New Directions in Archaeology. C.U.P. Cambridge: 9-20.

Ruiz, A. (1978): "Los pueblos iberos delAlto Guadalquivir. Análisis de un proceso de transición". Cuadernos de Prehistoria de la Universidad de Granada, 3: 255-278.

- (1987): "Ciudad y territorio en el poblamiento ibérico del Alto Guadalquivir". Coloquio Los asentamientos ante la romanización. Ministerio de Cultura y Casa de Velázquez. Madrid: 1-20.

- (1993): "Etnogénesis de las poblaciones pre-romanas de Andalucía Oriental". En M. Almagro-Gorbea y G. Ruiz Zapatero (eds.): Paleoetnología de la Península Ibérica. Complutum, 2: 101-118.

T. P., 55, n. ${ }^{\circ} 2,1998$ 
- (1995): "Plaza de Armas de Puente Tablas: New Contributions to the Knowledge of Iberian Town Planning in the Seventh to Fourth Centuries BC". Proceedings of the British Academy, 86: 89-108.

Ruiz, A. y Molinos, M. (1988): "Informe de la campaña de 1988 en el Cerro de la Plaza deArmas de Puente Tablas (Jaén)". Anuario Arqueológico de Andalucía /1988, II: 179-184.

- (1989): "Informe de la campaña de 1989 en el Cerro de la Plaza de Armas de Puente Tablas (Jaén). Estudio de materiales". Anuario Arqueológico de Andalucía / 1989, II: 402-408.

- (1990): "Informe de la campaña de 1989 en el Cerro de la Plaza de Armas de Puente Tablas (Jaén)". Anuario Arqueológico de Andalucía / 1990, II: 216-224.

- (1993): Los Iberos. Análisis arqueológico de un proceso histórico. Ed. Crítica / Arqueología. Barcelona.

SÁNCHEZ, C. (1992): El comercio de productos griegos en Andalucía oriental en los siglos V y IV a.C: estudio tipológico e iconográfico de la cerámica. Colección tesis doctorales n ${ }^{\circ}$ 145/92. Universidad Complutense. Madrid.

SÁnchez, J.; Mayoral, V.; Chapa, T.; Madrigal, A. y PereiRA, J. (e.p.): "Arqueología de laArquitectura en la cuenca alta del Guadalquivir. Cámaras funerarias y estructuras de habitación en época ibérica". Actas del II Congreso de Arqueología Peninsular, III (Zamora, 24-
27 septiembre 1996). Fundación Rei Afonso Henriques.

Schmarsow, A. (1893): Das wesen der Architektonischen Schöpfung. Leizpig.

SAmson, R. (ed.) (1990): The socialArchaeology of Houses. Edinburgh University Press, Edinburgh.

SANDERs, D. (1990): "Behavioral conventions and archaeology: methods for the analysis of ancient architecture". En S. Kent (ed.): Domestic Architecture and the use of Space. An interdisciplinary cross-cultural study. New Directions in Archaeology. C.U.P. Cambridge: 43-72.

StEadman, S.R. (1996): "Recent research in the Archeology of architecture: Beyond the Foundations". Journal of Archaeological Research, 4 (1): 51-93.

Tringham, R.; Brukner, B.; Kaiser, T.; Brorjevic, K.; Russell, N.; Steli, P.; Stevanovic, M. y Voytek, B. (1992): "The Opovo project: A study of socio-economic change in the Balkan Neolithic, second preliminary report". Journal of Field Archaeology, 19: 351-386.

VEN VAN DE, C. (1981): El espacio en arquitectura. Cátedra, Madrid.

WILK, R. y RATHJE, W. (1982): "Household archaeology". American Behavioral Scientist, 25: 617-639.

Yiannouli, E. y Mithen, S. (1986): "The real and random architecture of Siphnos: analysing house plans using simulation". Archaeological Review from Cambridge, 5 (2): 167-180. 